\title{
Assessment of source contributions to seasonal vegetative exposure to ozone in the U.S.
}

\author{
Kateryna Lapina, ${ }^{1}$ Daven K. Henze, ${ }^{1}$ Jana B. Milford, ${ }^{1}$ Min Huang, ${ }^{2,3}$ Meiyun Lin,, 4 \\ Arlene M. Fiore, ${ }^{6}$ Greg Carmichael, ${ }^{3}$ Gabriele G. Pfister, ${ }^{7}$ and Kevin Bowman ${ }^{2}$ \\ Received 17 September 2013; revised 5 November 2013; accepted 1 December 2013; published 14 January 2014.
}

[1] W126 is a cumulative ozone exposure index based on sigmoidally weighted daytime ozone concentrations used to evaluate the impacts of ozone on vegetation. We quantify W126 in the U.S. in the absence of North American anthropogenic emissions (North American background or "NAB") using three regional or global chemical transport models for May-July 2010. All models overestimate W126 in the eastern U.S. due to a persistent bias in daytime ozone, while the models are relatively unbiased in California and the Intermountain West. Substantial difference in the magnitude and spatial and temporal variability of the estimates of W126 NAB between models supports the need for a multimodel approach. While the average NAB contribution to daytime ozone in the Intermountain West is $64-78 \%$, the average W126 NAB is only 9-27\% of current levels, owing to the weight given to high $\mathrm{O}_{3}$ concentrations in W126. Based on a three-model mean, NAB explains $\sim 30 \%$ of the daily variability in the W126 daily index in the Intermountain West. Adjoint sensitivity analysis shows that nationwide W126 is influenced most by $\mathrm{NO}_{x}$ emissions from anthropogenic ( $58 \%$ of the total sensitivity) and natural $(25 \%)$ sources followed by nonmethane volatile organic compounds $(10 \%)$ and $\mathrm{CO}(7 \%)$. Most of the influence of anthropogenic $\mathrm{NO}_{x}$ comes from the U.S. (80\%), followed by Canada (9\%), Mexico (4\%), and China (3\%). Thus, long-range transport of pollution has a relatively small impact on W126 in the U.S., and domestic emissions control should be effective for reducing W126 levels.

Citation: Lapina, K., D. K. Henze, J. B. Milford, M. Huang, M. Lin, A. M. Fiore, G. Carmichael, G. G. Pfister, and K. Bowman (2014), Assessment of source contributions to seasonal vegetative exposure to ozone in the U.S., J. Geophys. Res. Atmos., 119, 324-340, doi:10.1002/2013JD020905.

\section{Introduction}

[2] Accumulated exposure to elevated levels of ozone leads to detrimental effects on vegetation [e.g., Reich and

\footnotetext{
Additional supporting information may be found in the online version of this article.

${ }^{1}$ Department of Mechanical Engineering, University of Colorado Boulder, Boulder, Colorado, USA.

${ }^{2}$ Jet Propulsion Laboratory, California Institute of Technology, Pasadena, California, USA.

${ }^{3}$ Center for Global and Regional Environmental Research, University of Iowa, Iowa City, Iowa, USA.

${ }^{4}$ Atmospheric and Oceanic Sciences, Princeton University, Princeton, New Jersey, USA.

${ }^{5}$ Geophysical Fluid Dynamics Laboratory, NOAA, Princeton, New Jersey, USA.

${ }^{6}$ Department of Earth and Environmental Sciences and LamontDoherty Earth Observatory, Columbia University, Palisades, New York, USA.

${ }^{7}$ Atmospheric Chemistry Division, National Center for Atmospheric Research, Boulder, Colorado, USA.

Corresponding author: K. Lapina, ECME 114, 1111 Engineering Dr, University of Colorado Boulder, Boulder, CO 80309, USA. (kateryna.lapina@colorado.edu)

(C)2013. American Geophysical Union. All Rights Reserved. 2169-897X/14/10.1002/2013JD020905
}

Amundson, 1985; Chappelka et al., 1999; Schaub et al., 2005]. Thus, present-day ozone levels are shown to cause significant yield reduction for a number of major crops on a global scale, leading to substantial economic losses annually [e.g., Van Dingenen et al., 2009; Avnery et al., 2011]. Studies have also documented numerous other negative impacts on ecosystems, such as reductions in tree growth, decreases in photosynthetic rates, and visible foliar injuries on multiple plant species, including deciduous trees in eastern North America and coniferous trees in the western U.S. [e.g., U.S. EPA, 2006; Arbaugh et al., 1998; Schaub et al., 2005]. Recent research has focused on reduction of ozone levels through mitigation of conventional short-lived ozone precursors (e.g., $\mathrm{NO}_{x}$, nonmethane volatile organic compounds (NMVOCs), and $\mathrm{CO}$ ), as well as reduction in methane [Shindell et al., 2012; Avnery et al., 2013] and even cultivation of ozone-resistant crops to minimize crop production losses [Avnery et al., 2013]. In North America (NA) the economic loss due to ozone damage for four ozone-sensitive crops (wheat, rice, soybean, and maize) is estimated to be between 3 and 5.5 billion US dollars in 2000 [Van Dingenen et al., 2009], depending on the ozone metric used. Hollaway et al. [2012] have further demonstrated that while most of the crop yield loss can be mitigated through local emissions 
controls, transboundary impacts are not negligible, with SE Asian emissions responsible for $2.3 \%$ of crop yield loss for soybeans in North America in 2000.

[3] The Clean Air Act requires the U.S. Environmental Protection Agency (EPA) to set two National Ambient Air Quality Standards for criteria pollutants such as groundlevel ozone - a primary standard, which serves to protect human health, and a secondary standard with a purpose to protect ecosystems and crops. A number of metrics can be used to evaluate vegetative exposure to ozone, including seasonal $7 \mathrm{~h}$ and $12 \mathrm{~h}$ mean daytime ozone concentrations (M7 and M12, respectively), and seasonal cumulative exposure above 40 and $60 \mathrm{ppbv}$ (AOT40, which is the current standard in Europe, and SUM60, respectively). Cumulative metrics emphasizing high concentrations are considered to be better suited for relating vegetative response to ambient ozone exposure [U.S. EPA, 2013]. The metric considered for the secondary standard in the U.S. is W126, a biologically based index that estimates a cumulative ozone exposure over a 3 month growing season and applies sigmoidal weighting to hourly ozone concentrations [Lefohn and Runeckles, 1987; Lefohn et al., 1988]. An advantage of W126 over other cumulative metrics is that it does not employ a threshold but applies weights which increase with higher concentrations, potentially more detrimental for vegetation [U.S. EPA, 2013]. Several U.S. counties are projected to violate a potential W126 standard of 13 ppm-hours, even if they are not in violation of a primary standard set at $70 \mathrm{ppbv}$ [U.S. EPA, 2011]. Many of the counties with high W126 are located in rural areas, mostly in the West, that lack significant local emissions, and vegetative damage at these sites results from ozone or ozone precursors transported from other regions.

[4] From a regulatory standpoint, the U.S. EPA distinguishes between ozone formed from sources that could be controlled through emission regulations in North America and ozone that is not affected by such emissions - the North American Background (NAB). The NAB includes contributions from natural sources and long-range transport of ozone and its precursors from outside North America. Previous estimates of NAB found higher values in the mountainous western U.S. compared to those in the East [Fiore et al., 2003; Wang et al., 2009; Emery et al., 2012; Lin et al., 2012a] with the maximum daily average $8 \mathrm{~h}$ ozone (MDA8) NAB concentrations reaching 50-60 ppbv in spring and summer in the Intermountain West [Zhang et al., 2011; Emery et al., 2012] and occasionally being as high as 75 ppbv during stratospheric intrusion events [Lin et al., $2012 \mathrm{~b}$. NAB ozone was found to be correlated with total ozone in the West, contributing substantially to high-ozone days, while no such correlation was found in the East [Fiore et al., 2003; Zhang et al., 2011]. Because of the different nature of the metrics used for primary and potential secondary ozone standards and the fact that the attainment of the primary standard will not necessarily ensure the attainment of the W126-based standard, especially in rural regions, there is a need to estimate how NAB levels contribute specifically to W126.

[5] The North American Background can only be estimated by chemical transport models (CTMs). CTMs have been widely used for source sensitivity analysis of ozone pollution, with several general approaches being applied, including brute-force calculations, tracer tagging, and adjoint simulations. In the first approach, a perturbation is applied to emission sources; comparison to an unperturbed run is then used to infer their influence on model outputs [e.g., Jacob et al., 1999; Fiore et al., 2009]. The tagged tracer approach "tags" emitted pollutants according to their sources, e.g., stratospheric or Asian ozone tracers [Brown-Steiner and Hess, 2011]. The adjoint approach considers an infinitesimal variation of a scalar model output, e.g., mean ozone concentration in the U.S., and uses auxiliary equations to propagate sensitivities backward in time during a single adjoint model run to calculate the impact of multiple emission sources and model parameters [e.g., Sandu et al., 2005; Hakami et al., 2006]. The advantage of the adjoint approach is obtaining spatially resolved sensitivity information for individual emitted species for relatively low computational cost when a scalar model output is considered.

[6] Previous studies on W126 have found it to be a challenging ozone exposure metric to model due to the cumulative nature of the index and sensitivity to model errors for the elevated ozone concentrations where higher weights are applied [Tong et al., 2009; Hollaway et al., 2012]. Comparisons between the mean daily maximum $8 \mathrm{~h}$ average and W126 index also showed that W126 produces a stronger and more nonlinear response to perturbations in transported background ozone [Huang et al., 2013]. Because of this nonlinear nature and high sensitivity to model errors and perturbations, a multimodel approach is valuable for reducing model bias and for estimating uncertainty in W126 source attribution. Additionally, a multimodel approach is strongly recommended for NAB ozone estimation [McDonald-Buller et al., 2011]. In this work we estimate W126 in the absence of NA anthropogenic emissions for May-July 2010 using three chemical transport models: GEOS-Chem, AM3, and Sulfur Transport and Deposition Model (STEM). We also quantify spatially and species-resolved relative influences of multiple anthropogenic and natural emission sources on the nationwide W126 metric through application of the GEOS-Chem adjoint model.

\section{Methods}

\subsection{W126 and Selection of Study Period}

[7] The W126 ozone index is calculated by applying a sigmoidally shaped weighting to daytime (8:00-19:59 local time) hourly ozone concentrations and summing them to compute a W126 daily index (DI):

$$
\mathrm{DI}=\sum_{k=08: 00}^{19: 59} \frac{\left[\mathrm{O}_{3}\right]_{k}}{1+4403 e^{\left(-0.126\left[\mathrm{O}_{3}\right]_{k}\right)}}
$$

where $\left[\mathrm{O}_{3}\right]_{k}$ is hourly ozone concentration in ppbv. This weighting emphasizes high ozone concentrations while retaining middle and low ozone values. For example, the weights are 0.03 at 40 ppbv and reach 0.6 at an inflection point of $70 \mathrm{ppbv}$ (Figure 1). Ozone values of $\sim 100 \mathrm{ppbv}$ and above are weighted by 1 . Monthly W126 is determined by summing the daily index over all days in a given month, and annual W126 is the maximum sum during a consecutive 3 month period.

[8] The proposed air quality standard selects the 3 month period to obtain an annual W126 for a given location in 


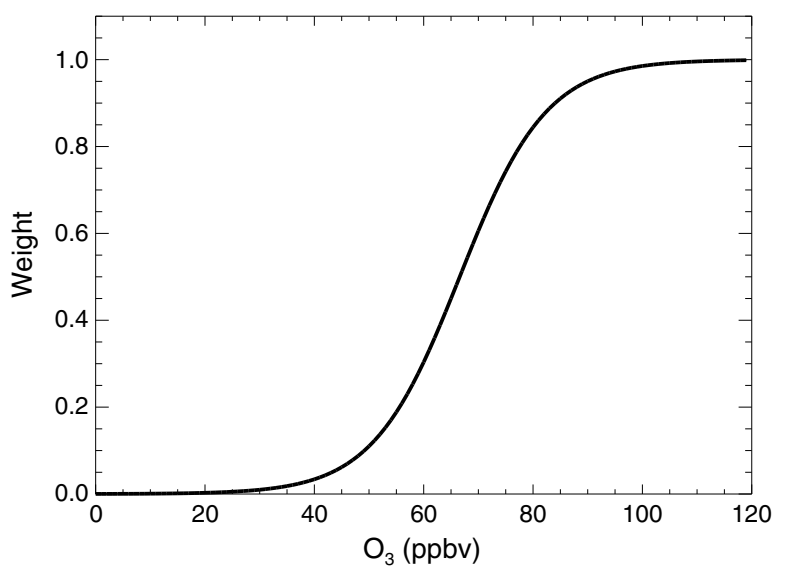

Figure 1. Weights applied to hourly ozone concentrations for W126 calculation.

each year, and the W126 design value is a 3-year mean of these annual values. (Further details on calculating the W126 index can be found on EPA website, http://www. epa.gov/ttn/analysis/w126.htm.) The season with the highest observed ozone concentrations depends on location [Fiore et al., 2003]. For example, the 3 month period with the maximum W126 value varies from April-May-June in Florida to July-August-September in parts of California. This makes modeling the maximum 3 month sum in the continental U.S. computationally expensive. Thus, in this work we focus on a fixed 3 month period, May-July 2010, which encompasses the maximum W126 3 month sum in many regions of the U.S. and corresponds to the mean value of the W126 season in the continental U.S.

\subsection{Observations}

[9] Hourly ozone observations used in this work are taken from the Air Quality System (AQS) and Clean Air Status and Trends Network (CASTNET). AQS (http://www. epa.gov/ttn/airs/airsaqs) contains ambient air pollution and meteorological data collected from thousands of monitoring stations across the U.S. CASTNET (http:/www.epa.gov/ castnet) monitors air quality in rural areas. The data in both networks are subject to strict quality control and quality assurance procedures. To compare models with observations, we exclude stations with less than $75 \%$ of complete days (thus omitting less than $2 \%$ of stations). For the remaining stations, monthly W126 is adjusted for missing observations by applying the ratio of the total number of hours in that month to the number of hours with valid observations. Figure 2a shows the sites used in this work. Data from $1145 \mathrm{AQS}$ and $66 \mathrm{CASTNET}$ monitoring sites are analyzed here.

\subsection{Models}

[10] Simulations from two global (GEOS-Chem and AM3) and one regional (STEM) chemical transport models are used to estimate the NAB for daytime ozone and W126. We perform two sets of simulations for each modelthe "base" scenario, which includes all emissions, and a sensitivity simulation with North American anthropogenic a) AQS and CASTNET data



c)



b)

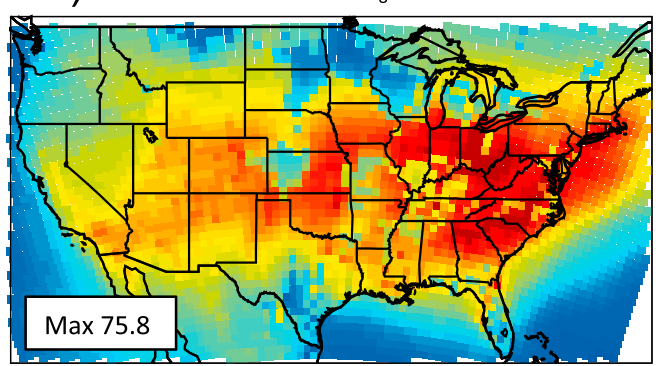

d)

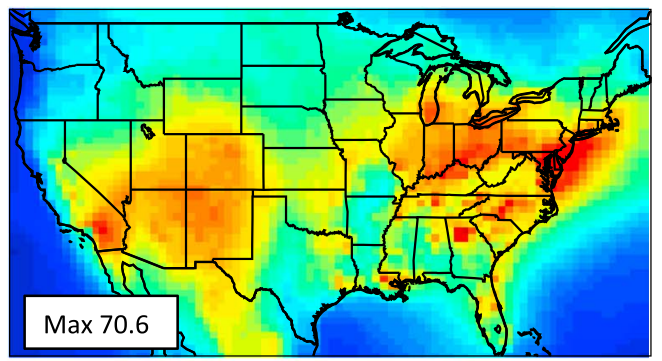



47

58

[ppb]

Figure 2. Three-month (May-June-July 2010) mean daytime (8 A.M. to 7 P.M. local time) surface ozone concentration from (a) CASTNET and AQS observations, (b) STEM, (c) AM3, and (d) GEOS-Chem. Color scales are saturated at the maximum values indicated in the legend. Black lines show the Atlantic, Intermountain West, and California regions discussed in text. 
Table 1. Description of Simulations/Diagnostics Used to Determine the 3 Month W126 Index in the U.S. and the North American Background and to Perform Source Attribution

\begin{tabular}{|c|c|c|}
\hline Type of Simulation & Description & Model \\
\hline Base & Emissions as described in the text and Table 2 & GEOS-Chem, STEM, AM3 \\
\hline NAB & $\begin{array}{l}\text { North American anthropogenic emissions } \\
\text { set to zero }\end{array}$ & GEOS-Chem, STEM, AM3 \\
\hline \multirow[t]{2}{*}{ Stratospheric tracer } & $\begin{array}{l}\text { Tagged stratospheric } \mathrm{O}_{3} \mathrm{~S} \text { tracer } \\
\text { originating from the stratosphere in base simulation }\end{array}$ & AM3 \\
\hline & $\begin{array}{l}\text { Cost function: mean } 3 \text { month W126 in the U.S., } \\
\text { emissions as in base simulation }\end{array}$ & GEOS-Chem ${ }^{\mathrm{a}}$ \\
\hline \multirow[t]{2}{*}{ Adjoint } & $\begin{array}{l}\text { Same as above but with applied observation-based } \\
\text { scaling factors }\end{array}$ & GEOS-Chem \\
\hline & $\begin{array}{l}\text { Cost function: mean } 3 \text { month daytime } \mathrm{O}_{3} \text { in the U.S., } \\
\text { emissions as in base simulation }\end{array}$ & GEOS-Chem \\
\hline
\end{tabular}

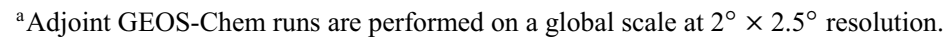

emissions set to zero- the "NAB" scenario. GEOS-Chem adjoint simulations and a tagged stratospheric ozone tracer from AM3 are also used for further source attribution (see Table 1). Surface hourly ozone output from each model is used to compute the W126 index for May-July 2010, as described above (section 2.1) for the base and NAB cases. Model outputs from the base simulations (with all emissions included) are evaluated using observations from the CASTNET and AQS data sets. The ozone concentrations discussed in the rest of this work will refer to daytime (8:00-19:59 local time) surface ozone values, for consistency with the W126 index. Descriptions of the models used in this work are given below and in Table 2, with further details available from references listed therein.

\subsubsection{GEOS-Chem}

[11] We use the GEOS-Chem model (www.geoschem.org) driven by GEOS-5 assimilated meteorology from the NASA Global Modeling Assimilation Office. We use global simulations with $2^{\circ} \times 2.5^{\circ}$ horizontal resolution as well as nested NA simulations with horizontal resolution of $1 / 2^{\circ} \times 2 / 3^{\circ}$, each with 47 vertical levels. Ozone concentrations are output from the midpoint of the first model layer, which is $\sim 120 \mathrm{~m}$ thick. GEOS-Chem includes detailed tropospheric chemistry with anthropogenic emissions from the 2005 National Emission Inventory (NEI2005) for the U.S. scaled to 2006, the Big Bend Regional Aerosol and Visibility Observational study [Kuhns et al., 2005] for Mexico, and from the Criteria Air Contaminants emission estimates for Canada. We use Asian anthropogenic emission estimates prepared for the NASA Intercontinental Chemical Transport Experiment (INTEX-B) mission in 2006 [Zhang et al., 2009b], and European emission estimates from the
European Monitoring and Evaluation Programme inventory. Biogenic emissions are from the Model of Emissions of Gases and Aerosols from Nature (MEGAN) version 2.0 [Guenther et al., 2006], and biomass burning emissions are taken from the Global Fire Emissions Database version 3 (GFED3) inventory [van der Werf et al., 2010], which includes emissions from both wildfires and fires caused by human activity. The lightning source of $\mathrm{NO}_{x}$ is calculated as a function of GEOS-5 deep convective cloud top heights and scaled to match OTD/LIS climatological observations [Murray et al., 2012]. $\mathrm{NO}_{x}$ emissions from soil are derived from the scheme by Wang et al. [1998]. We apply a linearized stratospheric chemistry mechanism as described by Murray et al. [2012] and a linearized stratospheric ozone (Linoz) parameterization [McLinden et al., 2000]. Wu et al. [2007] have shown that ozone production in GEOS-Chem can be significantly affected by the updates in the yield of organic nitrates from isoprene oxidation. While a more recent update included a $10 \%$ isoprene nitrate yield, the GEOS-Chem version used in this work employs $18 \%$. In the discussion below we consider the implications of using this value on the model results.

\subsubsection{STEM}

[12] The Sulfur Transport and Deposition Model (STEM) has been used and evaluated in a number of field campaigns [Carmichael et al., 2003; Adhikary et al., 2010; Huang et al., 2010]. The full-chemistry version of STEM (2K3) used here calculates gas-phase chemistry reactions based on the SAPRC 99 chemical mechanism [Carter, 2000] with thirty photolysis rates calculated online by the Tropospheric UltraViolet Radiation model. The STEM base and NAB simulations are performed over North America on a $60 \times 60 \mathrm{~km}$

Table 2. Description of the Models Used for W126 Analysis

\begin{tabular}{lcccccc}
\hline Model & $\begin{array}{c}\text { Horizontal } \\
\text { Resolution }\end{array}$ & Meteorology & Stratospheric $\mathrm{O}_{3}$ & $\begin{array}{c}\text { U.S. Anthropogenic } \\
\text { Emissions }\end{array}$ & $\begin{array}{c}\text { Biogenic } \\
\text { Emissions }\end{array}$ & $\begin{array}{c}\text { Biomass } \\
\text { Burning }\end{array}$ \\
\hline GEOS-Chem & $1 / 2^{\circ} \times 2 / 3^{\circ}$ & GEOS5 (offline) & $\begin{array}{c}\text { Parameterized } \\
\text { (Linoz) }\end{array}$ & $\begin{array}{c}\text { NEI2005 } \\
\text { scaled to 2006 } \\
\text { NEI2005 }\end{array}$ & MEGAN 2.0 & GFED3 \\
STEM $^{\mathrm{a}}$ & $60 \mathrm{~km} \times 60 \mathrm{~km}$ & WRF v.3.3.1 & $\begin{array}{c}\text { MEGAN 2.1 } \\
\text { conditions } \\
\text { (based on WRF } \\
\text { meteorology) }\end{array}$ & FINN \\
AM3 & $2^{\circ} \times 2.5^{\circ}$ & $\begin{array}{c}\text { Coupled, nudged to } \\
\text { from GEOS-Chem } \\
\text { Full stratospheric } \\
\text { chemistry/dynamics }\end{array}$ & $\begin{array}{c}\text { RCP8.5 for } \\
2010\end{array}$ & MEGAN 2.1 & GFED3 \\
\hline
\end{tabular}

a Boundary conditions for STEM are derived from global GEOS-Chem simulation at $2^{\circ} \times 2.5^{\circ}$ resolution.

${ }^{\mathrm{b}}$ NCEP-NCAR, National Centers for Environmental Prediction-National Center for Atmospheric Research. 
Lambert Conformal conic projection grid with 18 vertical layers from surface to top of the troposphere $(\sim 11-12 \mathrm{~km})$, with a $\sim 60 \mathrm{~m}$ thick surface layer. Meteorological fields are generated by the Advanced Research Weather Research and Forecasting Model (WRF-ARW) version 3.3.1 driven by National Centers for Environmental Prediction final analysis on $1^{\circ} \times 1^{\circ}$ grid every $6 \mathrm{~h}$ data (http://www.mmm. ucar.edu/wrf/OnLineTutorial/DATA/FNL/index.html). The physics options used for the WRF simulation are similar to Huang et al. [2013]. Anthropogenic emissions are taken from NEI2005. Biomass burning emissions are from the FINN inventory v1.0 (http://bai.acd.ucar.edu/Data/fire/; Wiedinmyer et al. [2011]) and are placed into multiple model layers. Biogenic emissions are generated by MEGAN version 2.1 based on the WRF meteorology (http://acd.ucar.edu/ guenther/MEGAN/MEGAN.htm; Guenther et al. [2012]). Lightning $\mathrm{NO}_{x}$ emissions are generated following the method described by Allen et al. [2012], with the flash rates determined by the WRF convective precipitation and scaled to the National Lightning Detection Network flash rates. The emissions are vertically distributed to multiple model layers, based on Ott et al. [2010]. STEM uses the time-varying lateral and top boundary conditions downscaled from the base and NAB $2^{\circ} \times 2.5^{\circ}$ GEOS-Chem simulations (saved hourly).

2.3.3. AM3

[13] The Geophysical Fluid Dynamics Laboratory AM3 global chemistry-climate model (GFDL AM3) nudged to reanalysis winds has been recently applied to quantify Asian and stratospheric influences on springtime high surface ozone events in the western U.S. [Lin et al., 2012b, 2012a]. The model includes fully coupled stratospheric and tropospheric chemistry, described in more detail by Lin et al. [2012b] and Naik et al. [2013]. Analysis of daily ozonesonde and surface measurements during the CalNex field campaign in May-June 2010 (http://www.esrl.noaa.gov/csd/projects/ calnex/) indicates that AM3 captures key features of ozone day-to-day variability in the free troposphere and at surface sites over the western U.S. and thus is a suitable tool for quantifying "episodic background" ozone. In this work, we use the AM3 base and NAB simulations at $\sim 200 \times 200 \mathrm{~km}^{2}$ horizontal resolution with 48 vertical levels from the surface to $0.01 \mathrm{hPa}$, with the first model layer being $\sim 70 \mathrm{~m}$ thick. The simulations use anthropogenic emissions from RCP8.5 [Moss et al., 2010] and biomass burning emissions from GFED3 [van der Werf et al., 2010] for 2010, as in Lin et al. (Footprints of decadal climate variability in ozone at Mauna Loa Observatory, submitted to Nature Geoscience, 2013). AM3 applies climatological soil $\mathrm{NO}_{x}$ emissions, whereas biogenic isoprene emissions (based on MEGAN2.1) and lightning $\mathrm{NO}_{x}$ are tied to the model meteorology [Naik et al., 2013]. In the NAB simulation, North American anthropogenic emissions of nonmethane ozone precursors and aerosols are set to zero.

\subsection{GEOS-Chem Adjoint}

[14] To estimate which specific species, sectors, and locations most influence ozone and W126 in the U.S., we apply the GEOS-Chem adjoint model [Henze et al., 2007] v34i. Adjoint modeling uses a computationally efficient approach for calculating sensitivities of an air quality metric $J$ (e.g., mean concentration) to a set of input parameters of the chemical transport model such as emissions [e.g., Giering and Kaminski, 1998; Sandu et al., 2005; Hakami et al., 2006]. The adjoint model of GEOS-Chem has been previously used for $\mathrm{O}_{3}$ source-receptor modeling [e.g., Zhang et al., 2009a; Walker et al., 2012; Parrington et al., 2012]. The adjoint model calculates the influence of emissions (or other parameters) on variations in the cost function as normalized adjoint sensitivities, $\lambda_{E_{i, m}}$ :

$$
\lambda_{E_{i, m}}=\frac{\partial J}{\partial E_{i, m}} \frac{E_{i, m}}{J}
$$

These sensitivities represent a fractional change in the cost function $J$ to a fractional change in emissions $E$ of source $m$ in location $i$ and are calculated about the current model state. For sensitivity analysis in this work, $J$ is defined as either the average 3 month cumulative W126 or daytime ozone over the continental U.S., as described in section 3.3.3 and Table 1. For W126 this can be expressed as

$$
J=\frac{1}{N} \sum_{i}^{N} \sum_{k}^{M} \mathrm{DI}_{i, k}
$$

where $\mathrm{DI}_{i, k}$ is a daily $\mathrm{W} 126$ index in location $i$ on day $k$, $M$ is the number of days (i.e., 92), and $N$ is the number of locations. Adjoint simulations are performed separately for each month, with sensitivities integrated backward in time for 1 month preceding the month in which the cost function is evaluated. This is done in order to fully account for the influence of emissions of ozone precursors. To obtain the 3 month normalized sensitivities discussed in this work, the sum of normalized sensitivities scaled by each month's cost function is divided by the sum of $J$ over 3 months. For further interpretation, sensitivity results are grouped by location, species, and emission sectors.

\section{Results and Discussion}

\subsection{Observed W126 in 2010}

[15] Figure 3 presents time series of the annual observed 3 month W126 index in the continental U.S. and three regions (California, Intermountain West, and Atlantic) plotted in Figure 2a. The mean W126 values for each region (solid lines) are obtained by averaging the maximum 3 month sums across all monitoring stations within the region. This 3 month period varies from station to station and is typically between April and September. For comparison, the means obtained by averaging the 3 month sum for May-June-July, i.e., with the period fixed across all stations, are plotted with dashed lines and are lower than the means obtained for the "true" W126 season for each year and station, as expected. The difference is especially large for California in 2010, where the ozone season varies widely based on location and the maximum W126 values were reached in June-July-August, on average. The highest 3 month W126 values are found in the California region during all 5 years. There is a significant degree of interannual variability for all regions with the overall decreasing trend. All regions except California exhibit a minimum in 2009, which was a low-ozone year across the U.S. [CASTNET 2009 report, 2011]. The second lowest 3 month W126 in the U.S. occurred in 2010 , at least partially due to the unusually 


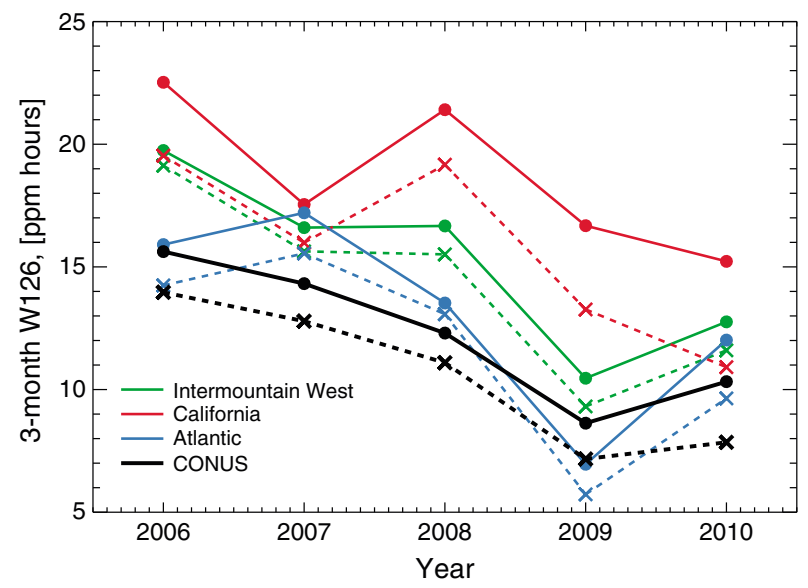

Figure 3. Time series of the spatially averaged 3 month W126 index from AQS and CASTNET in the continental U.S. and selected regions. Solid lines show the mean W126 calculated for the maximum W126 3 month sum at each station for a given year; dashed lines show the means for W126 in May-June-July.

wet conditions in spring and summer of 2010 according to the NOAA National Climatic Data Center (see http://www. ncdc.noaa.gov/temp-and-precip/).

\subsection{Model Performance for Daytime Ozone and W126}

[16] We first compare base-case simulations to observations. Figure 2 shows the 3 month mean of the observed daytime ozone from CASTNET and AQS and corresponding estimates from each model. The highest average daytime ozone is observed in California and in the mountain sites in the West. The spatial distribution of daytime ozone varies among the models. This is due to the differences in their meteorology, stratospheric influences, chemistry (such as the treatment of isoprene nitrates), and emissions (Table 2). A large overestimation of daytime ozone in the eastern U.S. is apparent in all models. STEM overpredicts $\mathrm{O}_{3}$ levels in the Iowa-Kansas-Oklahoma area. This bias is likely to be associated with meteorological fields and representation of land surface characteristics that affect physical processes as well as biogenic emissions in the model.

[17] The W126 index exhibits spatial patterns similar to daytime ozone (Figure 4) but with the regions of low and high ozone greatly emphasized due to the sigmoidal weighting of the W126 function. Even though the May-July W126 index does not always correspond to the maximum 3 month W126 sum for analyzed locations, a number of sites experience W126 levels exceeding those that have been considered for the secondary standard (7-15 ppm-hours) during this period. The maximum W126 index of 45 ppm-hours is observed in San Bernardino County, California. California exhibits the strongest W126 gradients; models are known to have difficulties reproducing spatial features of ozone in this region due to complex topography and failure to simulate ventilation of coastal pollution [e.g., Fiore et al., 2002]. STEM and GEOS-Chem are able to resolve more spatial features in daytime ozone in this region compared to the coarse-grid AM3 simulation. Model resolution is especially important for the W126 metric as it exhibits sharper spatial gradients compared to the mean daytime ozone. Observed
W126 is also high in the eastern part of the country (up to 25 ppm-hours) where the models tend to overestimate W126 by a factor of 2 to 4 .

[18] We also evaluate the daily time series of the mean daytime ozone and W126 daily index in each study domain; see Figure 5. Each model was first sampled at its native resolution at the time and location of observations followed by spatial averaging on a daily basis over the monitoring sites within the region. The three-model mean and standard deviation were then calculated based on model daily means for the region. Table 3 summarizes the regional 3 month means and temporal correlation coefficients between the observed and simulated daily values for individual models and for threemodel means. The NAB values estimated for both daytime ozone and the W126 daily index are also given. The models reproduce day-to-day variability in the daytime ozone and W126 daily index well, with the exception of AM3 in California $(r=0.47$ for ozone and $r=0.22$ for W126), where AM3 also has a positive bias of $\sim 10 \mathrm{ppbv}$. Lin et al. [2012b, 2012a] previously reported high bias in the $50 \times$ $50 \mathrm{~km}$ AM3 simulations for April-June 2010 in the western U.S., which they attributed to the combined influence from missing $\mathrm{O}_{3}$ sinks and model limitations in resolving mesoscale meteorology. We could not use the $50 \times 504 \mathrm{~km}$ AM3 simulations in this analysis, as results for July 2010 were not available. However, comparing the nested and coarse GEOS-Chem results suggests that using the coarser AM3 simulations may not significantly affect the model's ability to represent large-scale patterns. For GEOS-Chem, we found that while the fine resolution improved the representation of spatial patterns, especially in California, the choice of resolution did not affect the ability to simulate dayto-day variability in ozone and W126 over the study regions.

[19] The three-model ozone mean (red line in Figure 5) overestimates the observations (black) over the Atlantic region on a daily basis by $\sim 15$ ppbv. The bias in daily W126 (and, subsequently, the 3 month index) appears to result from persistent bias in daytime ozone (as opposed to being driven by a few large events). Additionally, model performance for W126 is worse than for the mean daytime ozone because of disproportionate sensitivity to model errors at the high end of the ozone concentration range [Tong et al., 2009; Hollaway et al., 2012]. This effect also leads to degraded correlation between observations and models compared to daytime ozone (Table 3). Using the reduced major axis (RMA) twosided regression technique [Ayers, 2001; Draper and Smith, 1998] for the three-model mean in the Atlantic region, we obtain the RMA slope of 1.9 and intercept of 159 ppbv-hours for W126 $(r=0.71)$, while simulations in California and the Intermountain West are relatively unbiased (slope of 1.1 and intercept of 3 ppbv-hours, $r=0.66$, and slope of 0.92 and intercept of 58 ppbv-hours, $r=0.69$, respectively).

[20] Bias of $>10 \mathrm{ppbv}$ in the eastern U.S. in summer is a well-known issue for chemical transport models [Fiore et al., 2009; Reidmiller et al., 2009]. Positive biases of 9-20 ppbv have been found for MDA8 ozone in that region in the multimodel Hemispheric Transport of Air Pollution (HTAP) study of Reidmiller et al. [2009] in summer 2001. Recent analysis of Zhang et al. [2011] presented a rather unbiased GEOS-Chem analysis for spring and summer of 2006, which can be at least partially explained by the difference between the years modeled, with 2010 
a)



c)

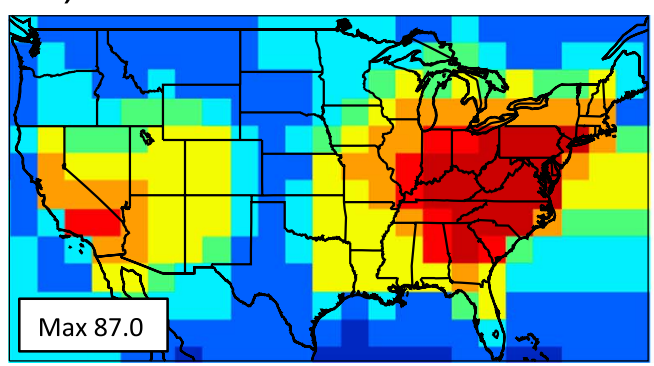

b)

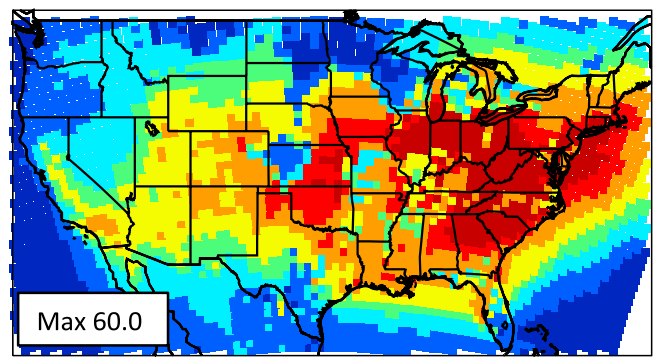

d)

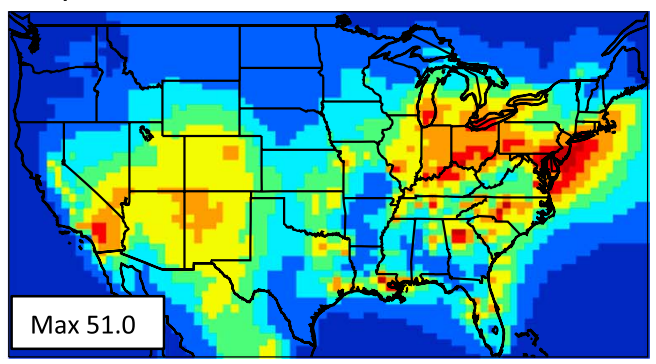

$\begin{array}{llllllllll} & 0 & 3 & 7 & 11 & 15213037 & 45 & \text { ppm hrs }\end{array}$

Figure 4. Three-month W126 index from (a) CASTNET and AQS observations, (b) STEM, (c) AM3, and (d) GEOS-Chem. Color scales are saturated at the maximum values indicated in the legend.

being a significantly lower-ozone year compared to 2006 (e.g., Figure 3). GEOS-Chem reproduces well the total amount of precipitation in May-July 2010 compared to the National Atmospheric Deposition Program National Trends Network (NADP NTN) observations (available at http:// nadp.sws.uiuc.edu); hence, it is unlikely that the bias is caused by missing precipitation events, even though conditions in some northeastern states were unusually wet. We find that when we decrease U.S. $\mathrm{NO}_{x}$ emissions by $30 \%$ in GEOS-Chem, ozone levels are reduced by 5 ppbv on average, implying that some of the model bias could be due to relatively recent emission reductions that are not reflected in the emission inventories used [e.g., Russell et al., 2012]. There is also indication that GEOS-Chem routinely underpredicts ozone dry deposition in the northeastern U.S., which may also contribute to the high-ozone bias in that region (D. Jones, personal communication, 2013). The bias in GEOSChem would be further enhanced, with the largest increases of up to $5 \mathrm{ppbv}$ in the southeastern U.S., if we updated the isoprene nitrate yield to $10 \%$. The impact of model bias on the source apportionment in this work is discussed in section 3.3.3.

\subsection{Source Sensitivity Analysis}

\subsubsection{Modeled Ozone and W126}

\section{North American Background}

[21] The spatial distribution of the NAB and its percent contribution to daytime ozone from each model is shown in Figure 6. The results are similar to the estimates reported previously for similar ozone metrics in springsummer [Fiore et al., 2003; Zhang et al., 2011; Emery et $a l ., 2012]$, with the highest values occurring in the western U.S. We took the ratio of the U.S.-averaged NAB to the base-case result for each model and found a range of 56$67 \%$ for the NAB contribution to the 3 month mean daytime ozone for three CTMs. For the Intermountain West region this range is $64-78 \%$. For individual locations the NAB contributions vary between 30 and $80 \%$ for a May-June-July daytime ozone mean. These numbers are within the range that can be estimated from Fiore et al. [2002], e.g., 40$70 \%$ for the mean afternoon ozone in 2001 and $\sim 70 \%$ for MDA8 at the Intermountain West sites in summer of 2006 [Zhang et al., 2011].

[22] The magnitude of the NAB ozone varies significantly among the models, with NAB in STEM being $\sim 10$ ppbv lower, on average, than NAB in GEOS-Chem, especially in the Atlantic and Intermountain West regions. Base-case STEM ozone was higher than observed in these regions. Two main factors could have been responsible for the low NAB in STEM-emissions from natural sources and transported background ozone, i.e., ozone from the extraregional contributions. Transported background ozone includes ozone and its precursors from the lower stratosphere and outside of North America and is important for NAB ozone in spring and summer [Huang et al., 2010, 2013]. This background is included in the top and lateral boundary conditions used by STEM for both base and NAB simulations. However, in this work they are provided by GEOS-Chem, which has significantly higher NAB ozone than STEM, and therefore the transported background cannot account for the difference between these two models. We conducted individual STEM sensitivity simulations for the base case where NA biogenic, biomass burning, and lightning emissions were set to zero (not shown). The results indicate that surface ozone in the U.S. is most sensitive to biogenic emissions (soil $\mathrm{NO}_{x}$ and biogenic hydrocarbons), 

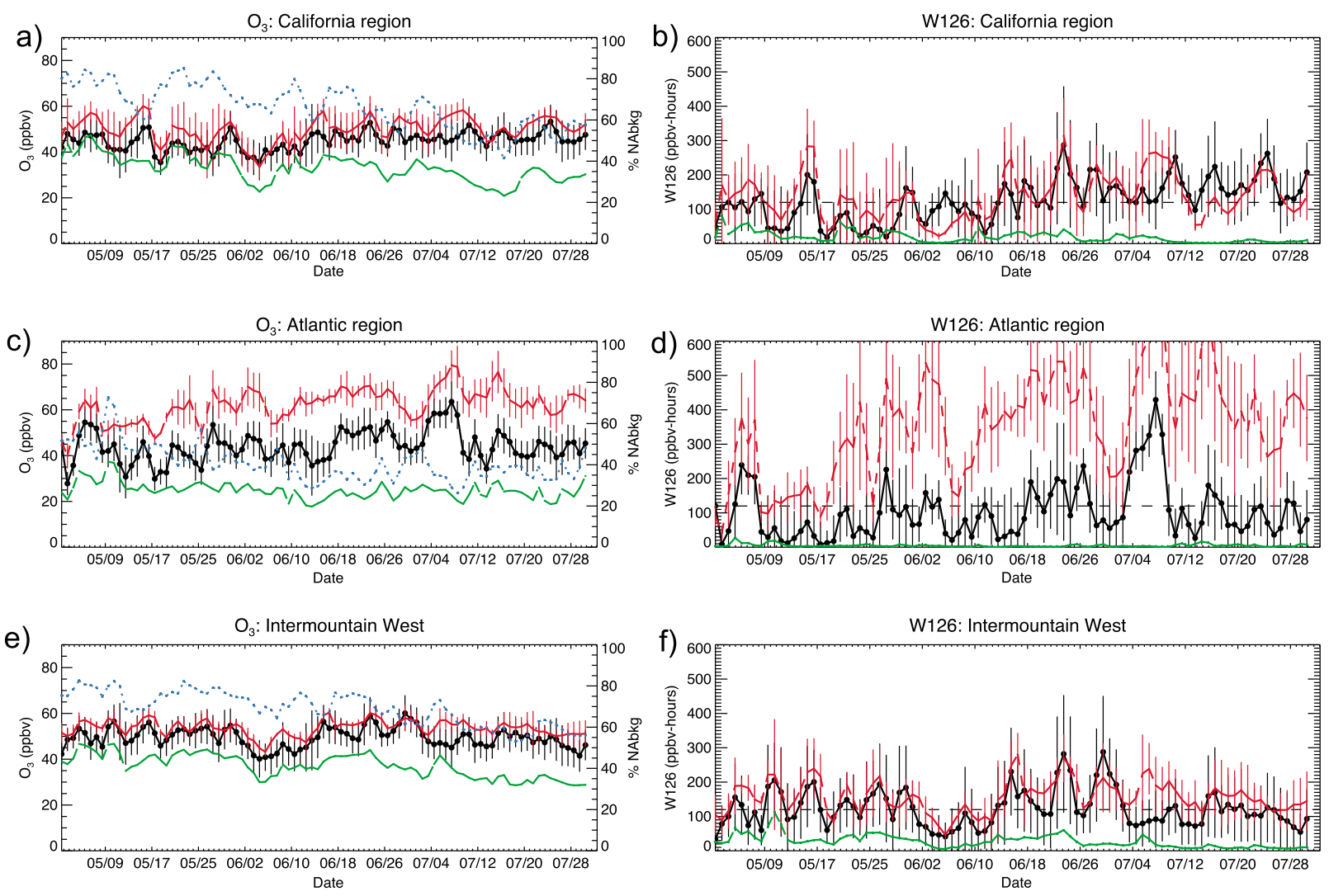

Figure 5. May-July 2010 time series of the observed and three-model mean \pm standard deviation for (left) daytime ozone and (right) daily W126 index for the (a, b) California, (c, d) Atlantic, and (e, f) Intermountain West regions. Observations from AQS and CASTNET are shown in black; model results (from three models) are shown in red. The three-model means for the North American background ozone and W126 are shown in green. The percentage contribution of the North American background to the total ozone is also shown (blue dotted line, right axis). Black dashed lines are drawn at levels above which a constant daily W126 would lead to exceedance of an 11 ppm-hours standard (i.e., DI = 120 ppbv-hours). See Figure S1 in the supporting information for individual model results.

with sensitivities showing strong spatial and temporal variability. This implies that uncertainties in the biogenic emissions are of a greater importance than uncertainties in other NA natural sources.

[23] Figure 7 shows the NAB estimate for the 3 month W126 metric. The three models predict low W126 values in the absence of North American anthropogenic emissions, with most locations below 3 ppm-hours, well below levels considered for the W126-based secondary standard. NAB is less than $6 \%$ of the base-case W126 in the East and up to $35 \%$ in the West (Figure 7). The mean NAB values for W126 over the entire contiguous U.S. for the three models are in the range of $4-12 \%$ of total W126. For the Intermountain West region, the mean W126 NAB value for the three models is in the range of $9-27 \%$. These values are low compared to the NAB contribution to the mean daytime ozone and are due to the highly nonlinear W126 dependence on ozone, which results in W126 for the base case being

Table 3. Means and Coefficients of Correlation for Observed and Modeled Daytime Ozone (ppbv) and W126 Daily Index (ppbv-hours) in Studied Regions ${ }^{\mathrm{a}}$

\begin{tabular}{|c|c|c|c|c|c|c|c|c|c|c|c|c|}
\hline \multirow[t]{3}{*}{ Region } & \multicolumn{4}{|c|}{ California } & \multicolumn{4}{|c|}{ Atlantic } & \multicolumn{4}{|c|}{ Intermountain West } \\
\hline & \multicolumn{2}{|r|}{$\mathrm{O}_{3}$} & \multicolumn{2}{|r|}{ W126 } & \multicolumn{2}{|r|}{$\mathrm{O}_{3}$} & \multicolumn{2}{|r|}{ W126 } & \multicolumn{2}{|r|}{$\mathrm{O}_{3}$} & \multicolumn{2}{|r|}{ W126 } \\
\hline & $r$ & Base (NAB) & $r$ & Base (NAB) & $r$ & Base (NAB) & $r$ & Base (NAB) & $r$ & Base (NAB) & $r$ & Base (NAB) \\
\hline AM3 & 0.47 & $55.6(36.8)$ & 0.22 & $206.7(36.9)$ & 0.65 & $64.9(29.2)$ & 0.60 & $411.7(10.2)$ & 0.57 & $53.8(39.6)$ & 0.48 & $167.4(47.0)$ \\
\hline STEM & 0.81 & $48.3(33.7)$ & 0.70 & $113.5(10.4)$ & 0.63 & $63.4(19.5)$ & 0.66 & $401.8(1.4)$ & 0.59 & $53.9(32.8)$ & 0.44 & $166.6(13.0)$ \\
\hline $\mathrm{GC}$ & 0.75 & $46.0(30.9)$ & 0.74 & $110.8(14.5)$ & 0.70 & $57.9(28.3)$ & 0.71 & $249.9(5.8)$ & 0.57 & $55.5(42.9)$ & 0.49 & $177.9(42.2)$ \\
\hline Three-model mean & 0.81 & $50.0(33.6)$ & 0.66 & $143.7(20.6)$ & 0.71 & $62.1(25.7)$ & 0.71 & $354.5(5.8)$ & 0.77 & $54.4(38.4)$ & 0.69 & $170.6(34.1)$ \\
\hline Observations & & 44.9 & & 125.9 & & 44.1 & & 102.8 & & 49.5 & & 122.5 \\
\hline
\end{tabular}

${ }^{a}$ Shown are coefficients of correlation, $r$, between the model (base case) and observations, and the mean values for each region for the base model run and North American background (in brackets), and for observations. 
a)

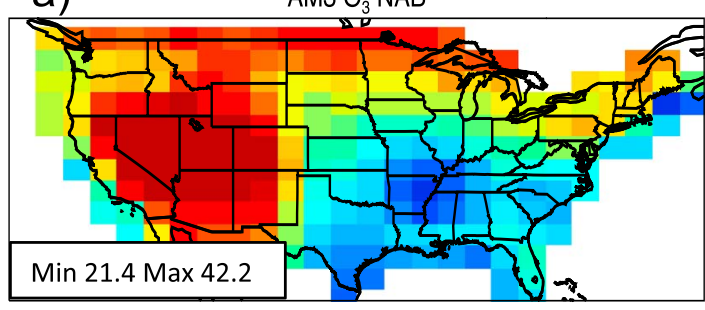

c)

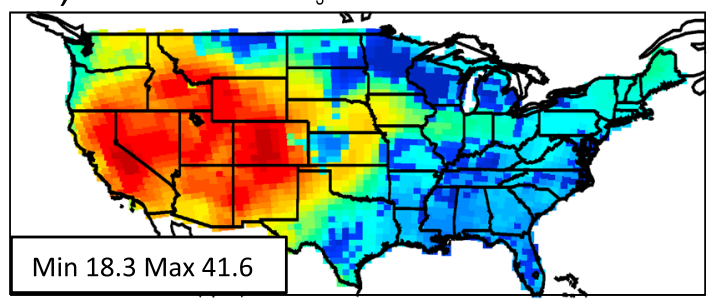

e)
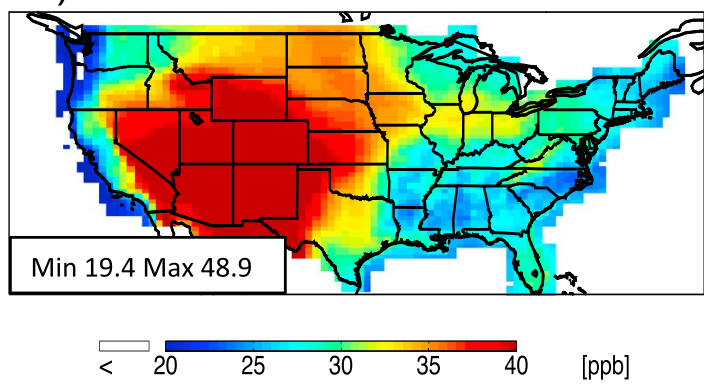

b)

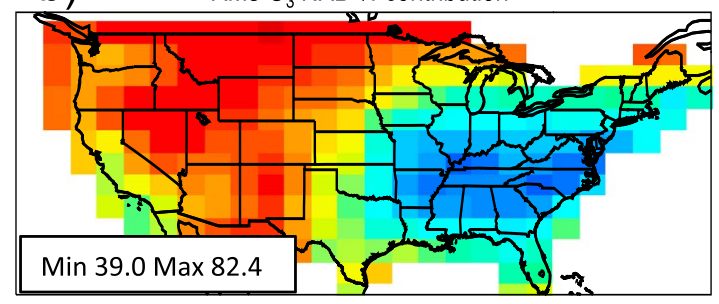

d)

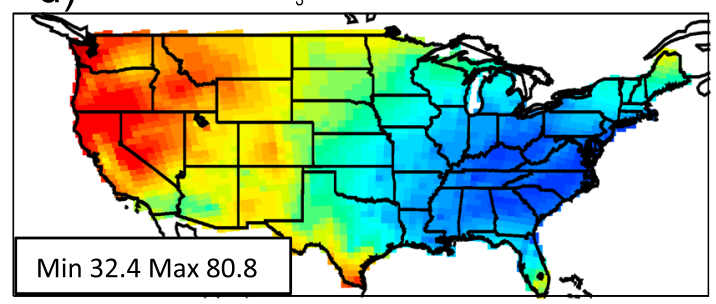

f) GEOS-Chem $\mathrm{O}_{3} \mathrm{NAB} \%$ contribution

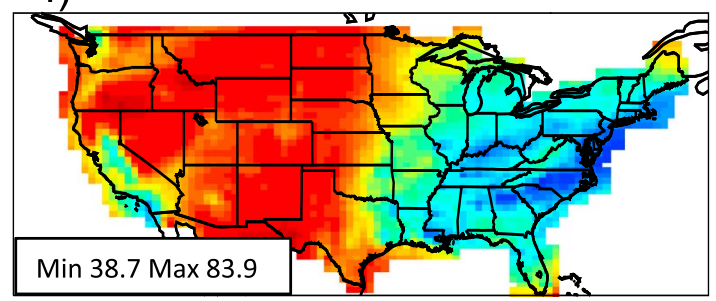

$[\%]$

Figure 6. The 3 month North American (left) daytime ozone background and (right) average percent contribution of NAB to daytime ozone estimated with (a, b) AM3, (c, d) STEM, and (e, f) GEOS-Chem models. Color scales are saturated at the minimum and maximum values indicated in the legend.

significantly larger than the sum of W126 estimated from the background ozone and W126 estimated from the ozone produced from the North American anthropogenic sources. Thus, it is important to realize that even though the background contribution to the daytime ozone is high at some locations, the fact that W126 is extremely low in the absence of North American anthropogenic emissions emphasizes the importance of these emissions. It is only after their addition to the background that ozone levels become significant enough to yield high W126. Further discussion of the implications of nonlinearity for source-attribution results in this work is given in section 3.3.5.

[24] Models differ on their predictions of the NAB behavior on the days with high W126 DI, with the largest disagreement in the Intermountain West region. AM3 and GEOS-Chem estimate that most of the variability in the $\mathrm{W} 126 \mathrm{DI}$ in this region is controlled by NAB $(r=0.91$ and $r=0.73$ for AM3 and GEOS-Chem, respectively), while STEM predicts no temporal correlation between the total W126 and NAB. When a three-model mean is used, W126 DI NAB explains $\sim 30 \%(r=0.55)$ of the daily variability in the W126 DI in the Intermountain West, which is on the lower end of the range of $20-54 \%$ reported earlier for MDA 8 at selected sites in the same region for spring and summer of 2006 [Zhang et al., 2011]. As evident from Figure 5, the
W126 NAB increases occasionally on days with high W126 daily index in the California region $(r=0.23$, based on threemodel mean) and there is no significant temporal correlation of NAB with the W126 DI in the Atlantic region where regional photochemical production is understood to be the most important contribution [Fiore et al., 2003; Zhang et al., 2011]. For each individual model there is a slight decrease in correlation between the NAB and W126 compared to correlation between the NAB and total daytime ozone. As NAB increases less than the total W126, no correlation is present between the NAB percent contribution and W126 for California and the Intermountain West, and there is a weak negative correlation between the NAB percent contribution and W126 for the Atlantic region $(r=-0.42)$, consistent with the findings of Henderson et al. [2012] for MDA8.

[25] To determine the extent to which model bias could affect estimates for the 3 month W126 NAB contribution, we apply a simple bias correction, to GEOS-Chem results only, for the California and Atlantic regions. We picked these regions because of the differences in model performance and because they represent cases with high and low NAB. We first sample the models at the locations of observations and find the NAB contribution for each region using the model results only, e.g., $\frac{\sum_{i} \mathrm{~W} 126_{\mathrm{NAB} i}}{\sum_{i} \mathrm{~W} 126_{\mathrm{BASE}}} \times 100 \%$, where $i$ includes all GEOS-Chem grid cells containing at least one station in the 
a)

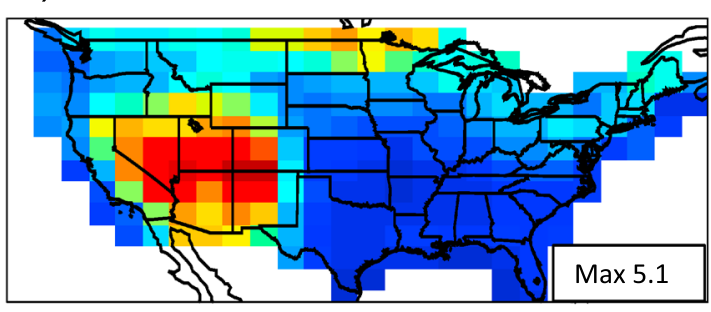

c)



e)

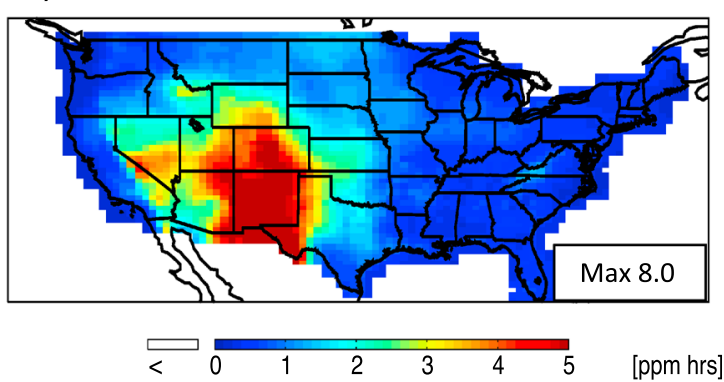

b) AM3 $W 126_{\text {NAB }} \%$ of $W 126_{\text {base }}$

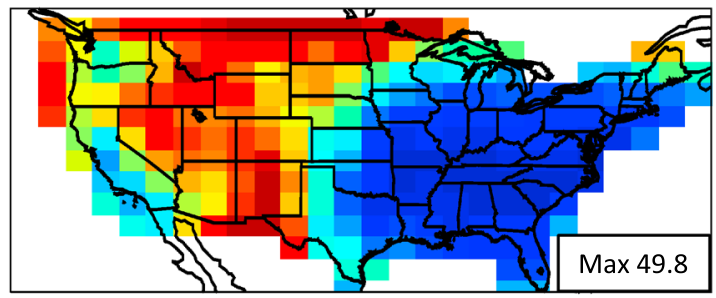

d)

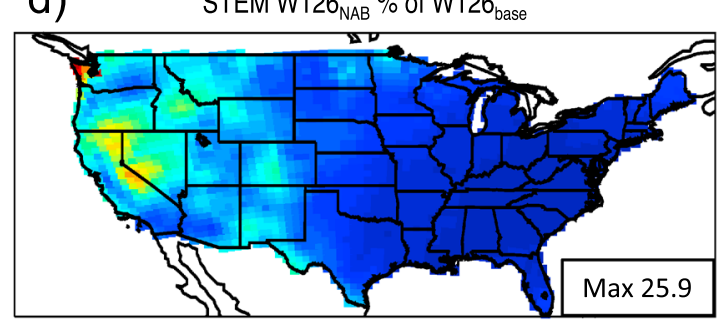

f) GEOS-Chem $W 126_{N A B} \%$ of $W 126_{\text {base }}$

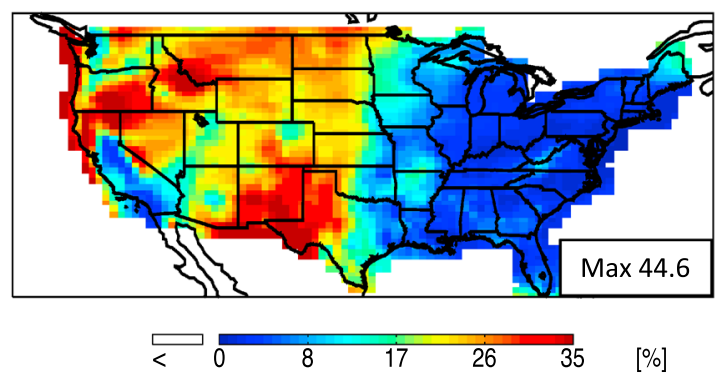

Figure 7. The 3 month North American (left) W126 background and (right) percent NAB of total W126 estimated with (a, b) AM3, (c, d) STEM, and (e, f) GEOS-Chem models. Color scales are saturated at the maximum values indicated in the legend.

region. We estimate these contributions to be $1.0 \%$ for the Atlantic region and $\mathbf{1 2 . 7 \%}$ for the California region. Next we modify the expression above and apply the observationbased correction factors in each region to obtain the NAB contributions as follows:

$$
\mathrm{NAB} \%=\sum_{i} \frac{\mathrm{W} 126_{\mathrm{NAB} i} \times \frac{\mathrm{W} 126_{\mathrm{OBS} i}}{\mathrm{~W} 126_{\mathrm{BASE} i}}}{\sum_{i} \mathrm{~W} 126_{\mathrm{OBS} i}} \times 100 \%
$$

where $\mathrm{W} 126_{\mathrm{OBS} i}$ is an observed value of $\mathrm{W} 126$ and $\mathrm{W} 126_{\mathrm{NAB} i}$ and $\mathrm{W} 126_{\mathrm{BASE} i}$ are estimates of the base and NAB W126 values at location $i$, respectively. Applying correction factors to NAB estimates in this way assumes that model bias is uniform across the base and NAB runs. The new NAB contributions are 1.2 and $14.4 \%$; thus, the applied correction results only in minor changes to the original estimates, likely owing to the fact that most model bias is in the East, where NAB is low.

\subsubsection{Impact of Stratospheric Ozone on W126}

[26] To investigate the stratospheric contribution to W126 levels, we use AM3, which includes fully interactive stratospheric and tropospheric chemistry. The AM3 stratospheric ozone tracer, $\mathrm{O}_{3} \mathrm{~S}$, is defined relative to a dynamically varying tropopause [Prather et al., 2011] and is used to tag $\mathrm{O}_{3}$ originating from the stratosphere. Through employing this technique with high-resolution $(\sim 50 \times 50 \mathrm{~km})$ AM3 simulations, Lin et al. [2012b] have previously demonstrated that stratospheric intrusions can have a significant impact on MDA8, especially at high-elevation sites in springtime.

[27] AM3 gives 3 month means of $\mathrm{O}_{3} \mathrm{~S}$ across the continental U.S. ranging from 4 to $17 \mathrm{ppbv}$ (mean of $10 \mathrm{ppbv}$ ). Thus, W126 estimated from $\mathrm{O}_{3} \mathrm{~S}$ directly is negligible $(<2 \%$ of total W126, on average) due to the low weights given to $\mathrm{O}_{3}$ less than $40 \mathrm{ppbv}$ in the W126 function. The coarse horizontal resolution of the AM3 model in this work was insufficient for more detailed analysis to resolve the temporal and spatial variability of $\mathrm{O}_{3} \mathrm{~S}$ and its influence on W126.

\subsubsection{Differentiating Emission Influences Using} Adjoint Sensitivities

[28] We apply the adjoint of GEOS-Chem to derive the spatially resolved first-order normalized sensitivities of the nationwide 3 month average daytime ozone and 3 month W126 to the model's emissions. The adjoint analysis is performed for the base-case run (with unperturbed emissions) twice - first with the cost function $J$ defined as the 3 month W126 and second with $J$ defined as the 3 month average daytime ozone, each averaged over the U.S. domain (Table 1). Due to computational expenses, the global-scale adjoint runs 
a)

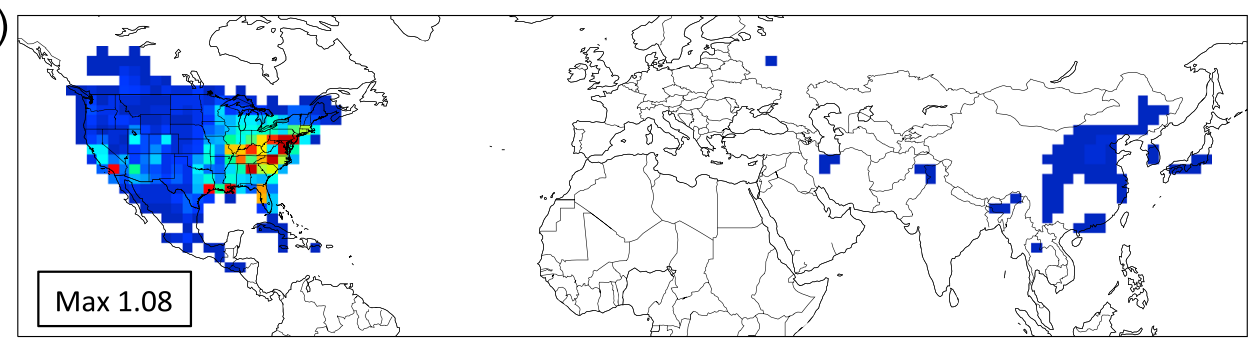

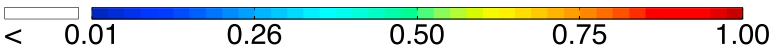

[\%]

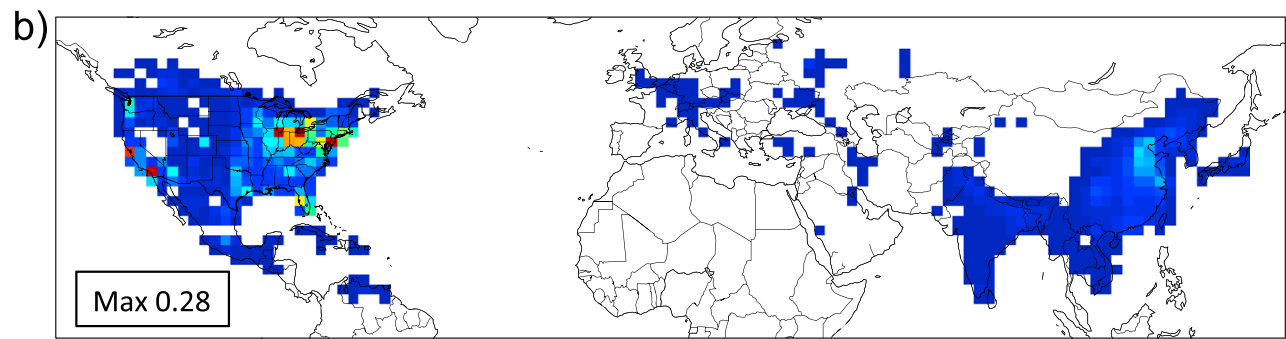

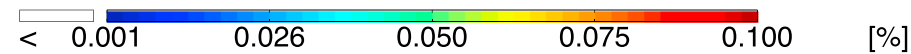

Figure 8. Sensitivities of May-July $2010 \mathrm{~W} 126$ in the U.S. to (a) anthropogenic $\mathrm{NO}_{x}$ and (b) anthropogenic $\mathrm{CO}$ emissions.

are performed at a horizontal resolution of $2^{\circ} \times 2.5^{\circ}$. While it is possible that this may limit our ability to resolve some smaller-scale processes, we find that the 3 month W126 metric obtained with this resolution is similar overall (i.e., an average difference of $0.7 \mathrm{ppm}$-hours for the base case) to the results obtained with a resolution of $1 / 2^{\circ} \times 2 / 3^{\circ}$ used in the rest of this work (see Figures S2 and S3 in the supporting information).

\subsubsection{Base-Case W126 Contributions}

[29] The adjoint sensitivities can be understood in terms of a fractional change in $J$ as a result of small fractional changes in emissions of the contributing species, such as $\mathrm{NO}_{x}$ and $\mathrm{CO}$, at each location. For each species, adjoint sensitivities identify emissions contributing the most to $J$. The highest $\mathrm{W} 126$ sensitivity is to anthropogenic $\mathrm{NO}_{x}$ emissions within the U.S. (Figure 8a) with little influence from abroad. Sensitivities to anthropogenic CO are more spread out, with relatively high values over parts of China, Mexico, and India (Figure 8b). While the magnitude of $\mathrm{NO}_{x}$ sensitivities in individual locations are $>20$ times higher than sensitivities to $\mathrm{CO}$, on average, the total $\mathrm{NO}_{x}$ influence is higher only by a factor of 10 due to the fact that $\mathrm{CO}$ sensitivities are more widely distributed throughout the Northern Hemisphere.

[30] The sensitivities can be aggregated to assess total W126 influences from source categories, including countries of origin, emission sectors, and emitted species. The sum of all normalized adjoint sensitivities for a function that is nonlinear with respect to model parameters can deviate from $100 \%$, as is the case here (section 3.3.5). In the discussion below we focus on the relative importance of emission sources, and all adjoint sensitivities are normalized by the sum of the total. Figure 9 shows sensitivities of W126 to emissions aggregated by sectors: anthropogenic, biomass burning, and natural, which includes isoprene emissions and $\mathrm{NO}_{x}$ emissions from lightning and soil. Soil emissions in the model include both the natural component as well as emissions from fertilized soil. However, fertilized emissions make a relatively small fraction of total soil emissions $(\sim 25 \%)$. The mean nationwide $\mathrm{W} 126$ is most sensitive to the anthropogenic $(58 \%)$ and natural $(25 \%) \mathrm{NO}_{x}$ emissions, followed by NMVOCs (10\%) and CO (7\%). Eighty percent of the sensitivity to $\mathrm{NO}_{x}$ anthropogenic emissions is within the U.S., followed by emissions in Canada (9\%), Mexico $(4 \%)$, and China (3\%). W126 is relatively insensitive to total isoprene $(1.3 \%$ of the total sensitivity) compared to the rest

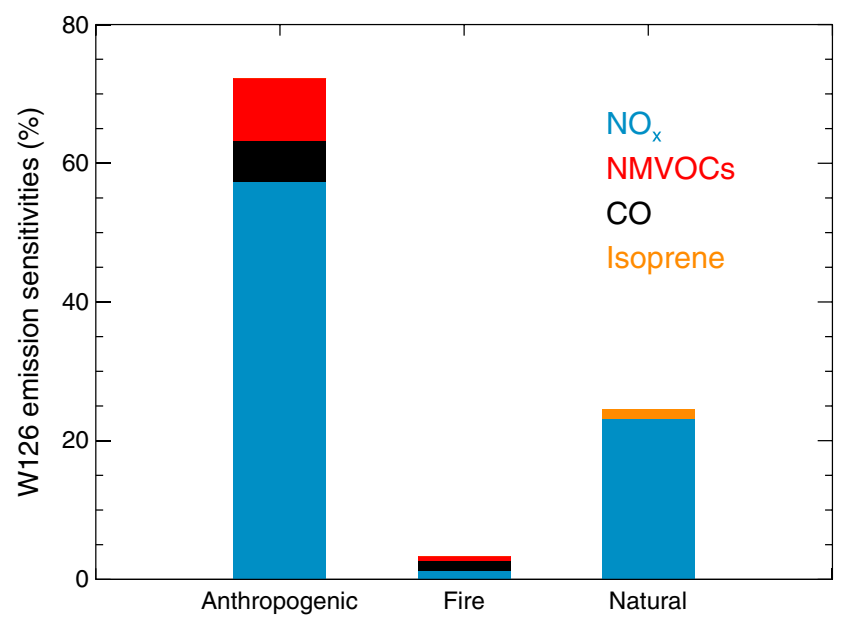

Figure 9. Sensitivities of May-July 2010 W126 in the U.S. to emissions aggregated by species and sectors. Sensitivities are normalized to the total and add up to $100 \%$. 


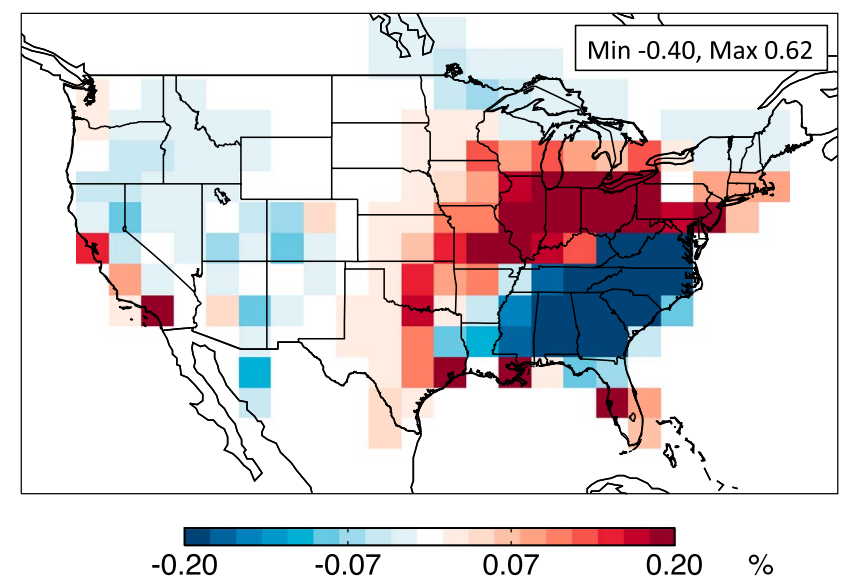

Figure 10. Sensitivities of May-July 2010 W126 in the U.S. to isoprene emissions in the U.S.

of the NMVOCs because isoprene sensitivities can be both negative and positive depending on location. Isoprene leads to ozone production in the presence of elevated $\mathrm{NO}_{x}$ concentrations, as modeled in the northeastern U.S. This results in high positive sensitivities as seen in Figure 10. Isoprene also destroys ozone through direct ozonolysis in areas with low $\mathrm{NO}_{x}$, as modeled in the southeastern U.S. The absolute magnitude of isoprene sensitivities in individual locations are, on average, $\sim 7$ times lower than sensitivities to anthropogenic $\mathrm{NO}_{x}$ emissions. Sensitivities of ozone to isoprene emissions depend, among other parameters, on the isoprene nitrate yield and the fate of isoprene nitrates assumed in the model. W126 sensitivities are more negative in this work due to the high isoprene nitrate yield value and assumption that isoprene nitrates act as a terminal sink for $\mathrm{NO}_{x}$. A 1 month sensitivity run with the reduced isoprene nitrate yield (10\%) exhibited enhanced positive isoprene sensitivities and weakening of the negative ones. Sensitivities will become even more positive if partial $\mathrm{NO}_{x}$ recycling for isoprene nitrates is allowed [Mao et al., 2013].

[31] Figure 11 shows sensitivities to anthropogenic $\mathrm{NO}_{x}$, $\mathrm{CO}$, and NMVOC emissions for W126 and daytime ozone aggregated by country. As the importance of the longrange transport of pollution relative to the local sources is determined by a species' lifetime, a greater fraction of $\mathrm{CO}$ influences are from remote regions for both $\mathrm{W} 126$ and ozone sensitivities, compared to $\mathrm{NO}_{x}$. Thus, GEOS-Chem indicates that China is the next most important W126 source region for $\mathrm{CO}(15 \%)$ after the U.S. (56\%). Emission influences for daytime ozone are overall similar to the influences for the W126 metric but with W126 being relatively less sensitive to long-range transport. This is due to the strong dependence of W126 on high ozone concentrations, which are typically observed in stagnant conditions when local emission sources play a dominant role [e.g., Fiore et al., 2003].

[32] The adjoint sensitivities discussed above correspond to the base-case state and are not expected to change significantly with moderate changes in emissions, as was shown for the episode-averaged $8 \mathrm{~h}$ ozone by Cohan et al. [2005]. To assess the degree to which sensitivities in different locations are influenced by emissions in other locations (i.e., secondorder cross sensitivity), we performed additional runs with emissions perturbed (halved or doubled) on a country or on a grid-scale basis. We find that sensitivities to U.S. emissions decreased by $63 \%$ when U.S. emissions were halved, implying that the same fractional change in emissions will result in the W126 relative response which is $63 \%$ lower than the W126 response for the base case. This change did not affect the fraction of response to change in U.S. emissions relative to change in emissions in other countries. These sensitivities were not affected significantly by changes in emissions outside of the U.S. (i.e., $<5 \%$ when emissions in either Canada, Mexico, or China were halved or doubled). Sensitivities to emissions outside of the U.S. do not exhibit significant interdependence; i.e., doubling or halving emissions in Mexico

a)

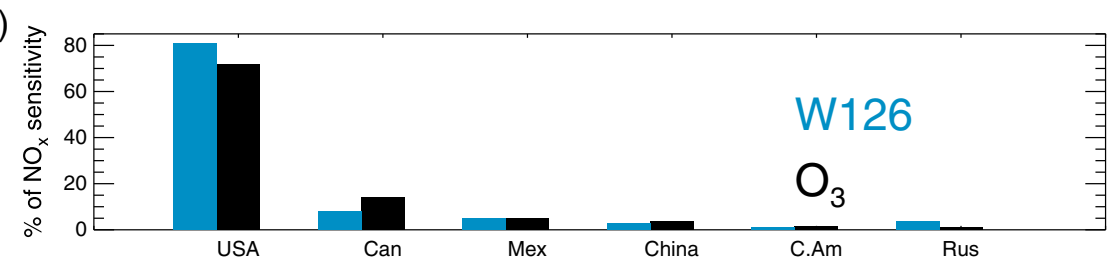

b)

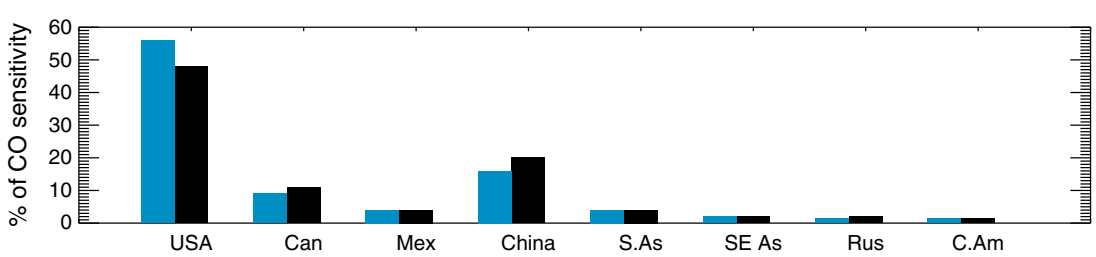

c)



Figure 11. Sensitivities to (a) $\mathrm{NO}_{x}$, (b) $\mathrm{CO}$, and (c) NMVOC emissions, aggregated by country for W126 (blue) and ozone (black). Sensitivities are normalized to the total and add up to $100 \%$ in each plot. 


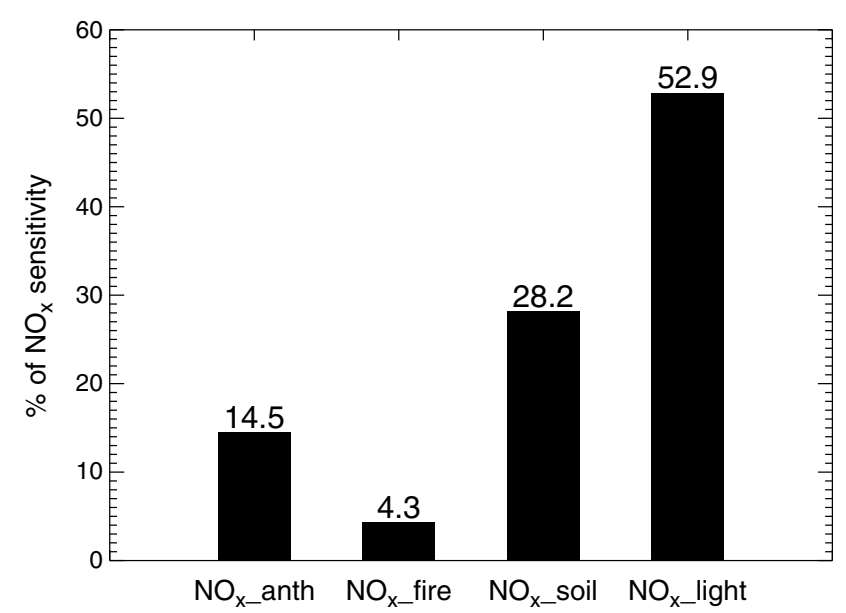

Figure 12. Sensitivities of the NAB component of W126 to $\mathrm{NO}_{x}$ emissions, aggregated by source categories. Sensitivities are normalized to the total and add up to $100 \%$.

has a relatively minor impact on the sensitivities of W126 to emissions in China $(<8 \%)$ and in Canada $(<2 \%)$. For single grid-cell perturbations outside the U.S. the W126 response was approximately linear implying that individual remote adjoint sensitivities can be used for a relatively accurate prediction of the resulting change. These results imply that the emission sensitivities obtained in this work for different regions are robust to emissions changes (or uncertainties in emission inventories) in other regions.

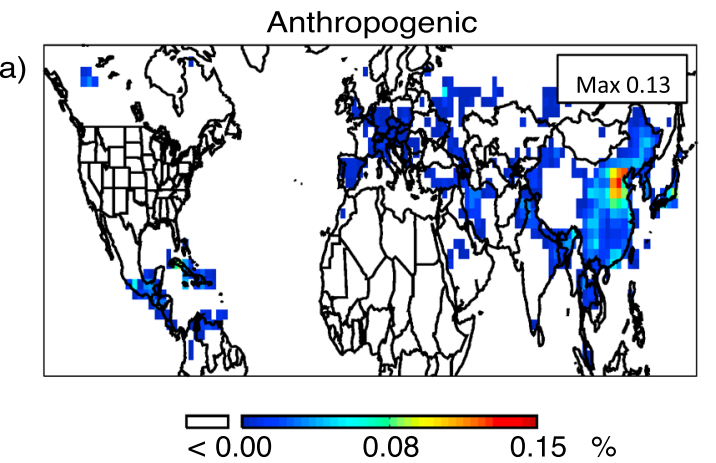

Soil

c)

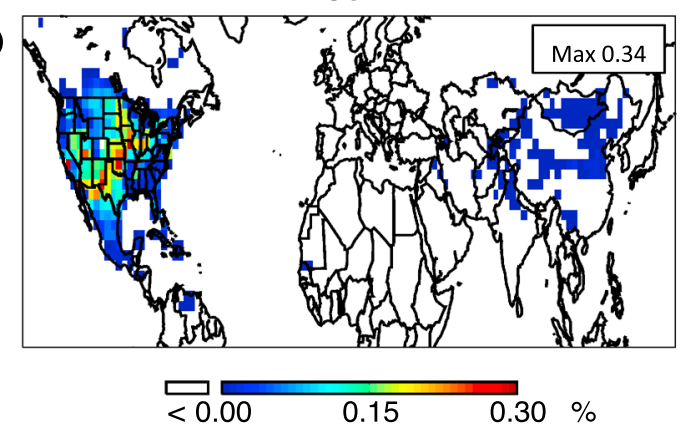

\subsubsection{NAB Contributions}

[33] To learn about emission sources contributing to the W126 NAB in the U.S., we can use the adjoint sensitivities obtained for the base run but include only sensitivities to emissions considered as part of the NA background, i.e., emissions from natural sources and anthropogenic emissions from outside NA. The alternative approach is to run the adjoint simulation with NA anthropogenic emissions set to zero. We find that both approaches provide similar results, with the main difference being that in the absence of the NA anthropogenic emissions the changes in chemical regime lead to an estimated negative isoprene response, except in a few localized areas with active biomass burning. Here we present the results for the base adjoint run, as information on natural sources influencing W126 at the present conditions is more relevant compared to the hypothetical NAB case. The main W126 sensitivities are to $\mathrm{NO}_{x}$ emissions $(79.8 \%$ of the total), followed by CO $(9.2 \%)$, NMVOCs $(7.3 \%)$, and isoprene influence of $3.6 \%$ (results normalized), with $\mathrm{NO}_{x}$ emissions from lightning and soil dominating the total $\mathrm{NO}_{x}$ influences (Figure 12). Long-range transport of anthropogenic $\mathrm{NO}_{x}$ emissions from outside NA plays a lesser role, with biomass burning $\mathrm{NO}_{x}$ having the least impact. The spatial distributions of these emissions and their sensitivities are very different (Figure 13). Thus, more than one third of the influence from lightning $\mathrm{NO}_{x}$ comes from outside of North America (40\%), while for soil emissions it is $<7 \%$. The average W126 sensitivity (\%) per unit $\mathrm{NO}_{x}$ emitted is highest for lightning emissions because this $\mathrm{NO}_{x}$ is generally emitted in more pristine conditions where ozone production efficiency is higher. Anthropogenic $\mathrm{NO}_{x}$ from outside

b)

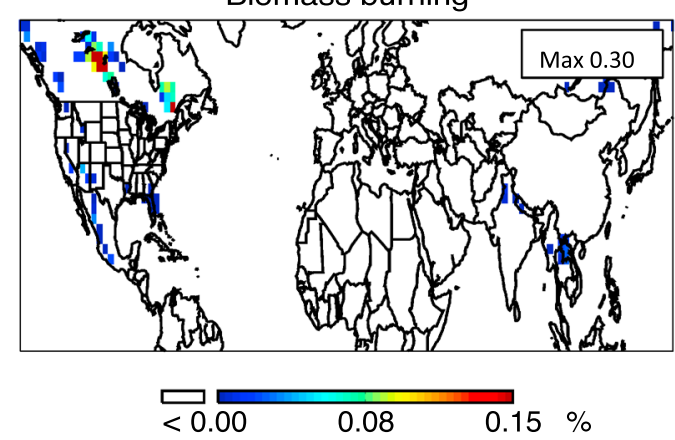

d)

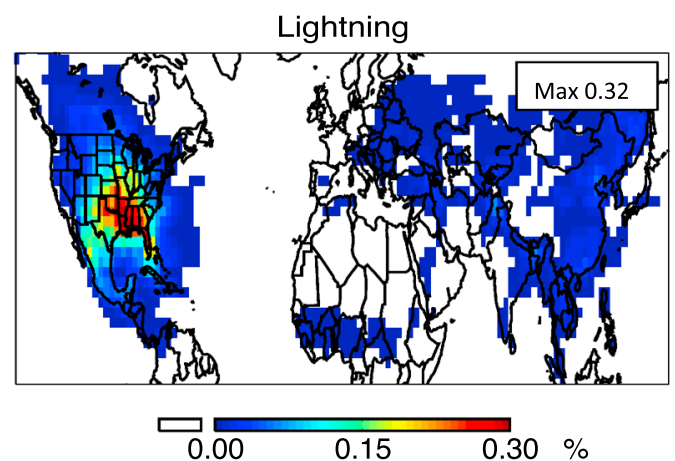

Figure 13. Normalized sensitivities of the NAB component of $\mathrm{W} 126$ to $\mathrm{NO}_{x}$ emissions estimates associated with (a) anthropogenic, (b) biomass burning, (c) soil, and (d) lightning. Color scales are saturated at the maximum values indicated in the legend. 


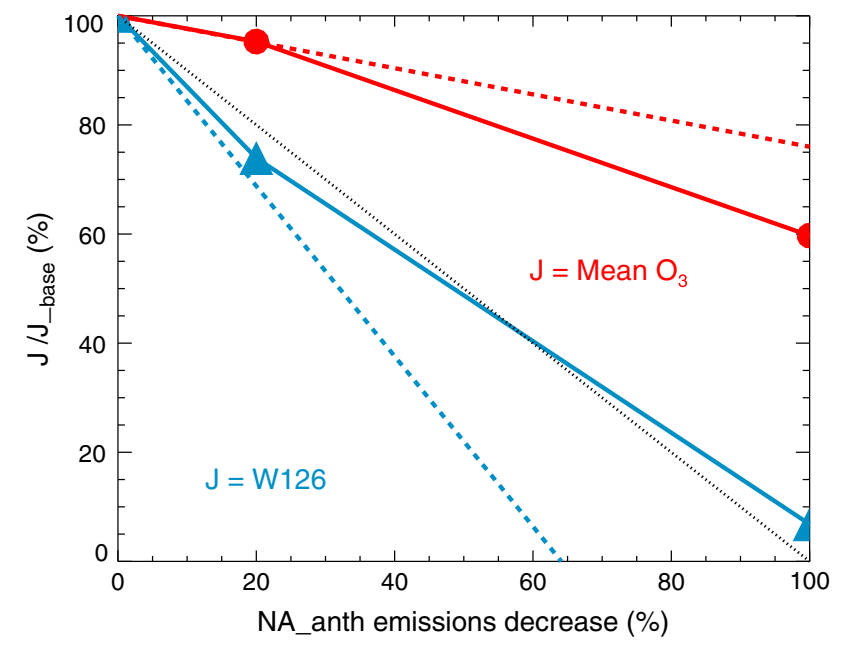

Figure 14. Change in the domain-averaged mean daytime ozone (red line with circles) and W126 (blue line with upward triangles) as a function of 20 and $100 \%$ perturbations in North American anthropogenic emissions (solid lines) in GEOS-Chem. Changes predicted from the adjoint sensitivities for the base case are shown with dashed lines. Plotted symbols indicate the relative change in cost function calculated using the perturbed emissions.

North America has the lowest \% sensitivity per fraction of total $\mathrm{NO}_{x}$ emitted, and the total impact of these emissions declines later in the summer, consistent with the seasonality of the impact of Asian emissions on North America [Liu et $a l ., 2003]$. The fire activity during May-July 2010 was relatively low (http://www.ncdc.noaa.gov/sotc/fire). $\mathrm{NO}_{x}$ from fires is likely to have a higher contribution in high-fire years, especially in the western U.S. [Mueller and Mallard, 2011; Jaffe, 2011].

\subsubsection{Effect of Bias Correction on Source-Attribution Results}

[34] Adjoint sensitivities are only as accurate as the GEOS-Chem representation of the processes influencing ozone and W126 are. To determine how GEOS-Chem model bias affects the W126 sensitivity results, we repeat the adjoint analysis with observation-based scaling factors applied to minimize model errors. In this new adjoint run, $J$ is defined only over model cells with existing observations, and the scaling factors at each location represent the ratio of the observed to modeled W126 value in that grid cell, $W 126_{\mathrm{obs}, i}$ and $W 126_{\mathrm{mod}, i}$, respectively:

$$
J=\frac{1}{N} \sum_{i}^{N} \sum_{k}^{M} \mathrm{DI}_{i, k} \times \frac{W 126_{\mathrm{obs}, i}}{W 126_{\mathrm{mod}, i}}
$$

We exclude $\sim 30 \%$ of cells in the continental U.S. due to lack of observations. The bias correction results in reduction of adjoint sensitivities mostly over the areas with W126 overestimation, such as the Atlantic region and Gulf Coast, and increased sensitivities over areas in California, the southeastern U.S., and parts of the West. However, the corrected sensitivities have only a minor $(<3 \%)$ effect for the percentages of total sensitivity aggregated by species, sector, or country, consistent with the bias-correction results presented in section 3.3.1.

\subsubsection{Comparison of Source Analysis Methods}

[35] It is important to distinguish between the results of source analysis quantified by setting emissions to zero and the results obtained by using a smaller change in emissions, e.g., 20\%, or from adjoint results that project responses from an infinitesimally small source perturbation. While the first approach measures the minimum obtainable level of an ozone metric in the absence of emission sources, the latter predicts the metric's response due to marginal changes in emissions. In the case of nonlinear dependence of the metric on emission sources, linear scaling of the first-order sensitivities to infer a response from a large perturbation will be subject to truncation errors. To assess the behavior of W126 in response to incremental changes in precursor emissions, we perform an additional GEOS-Chem simulation with the North American anthropogenic sources reduced by $20 \%$. We find that the mean daytime ozone had a greater response to the $100 \%$ reduction (38\%) compared to the response estimated by scaling up the response to a $20 \%$ reduction $(5 \times 4.4 \%=22 \%)$, consistent with previous work [Wu et al., 2009; Wild et al., 2012]. This is due to the fact that the daytime ozone concentrations have a nonlinear dependence on $\mathrm{NO}_{x}$ emissions, which can be represented by a concave function [Lin et al., 1988], with ozone becoming more sensitive to the remaining $\mathrm{NO}_{x}$ as emissions are reduced. For the 3 month W126 index this response is reversed $(92 \%$ W126 reduction if all NA emissions set to zero versus $113 \%$ obtained by scaling up the response to a $20 \%$ perturbation) due to the convex dependence of W126 on ozone concentrations in the range considered. As illustrated in Figure 14, extrapolation of the adjoint sensitivities to a $100 \%$ perturbation results in overestimated contribution of emissions for W126 and underestimated contribution for daytime ozone, similar to the case with $20 \%$ perturbation. The adjoint results presented in this plot are obtained by summing up the normalized sensitivities for all species from anthropogenic sources across North America, thus obtaining 24\% of $J$ for daytime ozone and $156 \%$ for W126. While aggregated marginal sensitivities should not be used to infer absolute contributions of emission sources to the air quality metric for the case when the relationship is nonlinear, they provide a valuable insight into the metric's response to small emission changes in a relatively unperturbed environment. For example, the adjoint method indicates that a $10 \%$ reduction in NA anthropogenic emissions will decrease the 3 month daytime ozone by $2.4 \%$ and $\mathrm{W} 126$ by $15.6 \%$. As was mentioned earlier, adjoint sensitivities are also more accurate when used on a grid-cell basis to provide the metric's response to single grid-cell perturbations outside of the U.S.

\section{Conclusions}

[36] We present model results from three CTMs to evaluate model abilities to simulate the W126 ozone metric in the U.S. and to quantify the contribution of emission sources to this metric. All models overestimate daytime ozone over the eastern U.S. on a daily basis, by $\sim 15$ ppbv. This high bias is further exacerbated by nonlinear weighting for the W126 index leading to an overestimation of the 3 month W126 by a factor of 2 to 4 in this region. In contrast, models are relatively unbiased over the California and Intermountain West regions. Simulating the W126 metric in these 
regions is arguably of greater value from a modeling standpoint for several reasons. First, compared to the eastern U.S., the West contains the largest NAB levels. Second, much of the West is relatively sparsely monitored from the point of view of vegetative exposure, with existing monitor locations designed around primary ozone standards. Last, of the counties presently monitored, a greater potential for disconnect between attaining primary versus W126-based ozone standards has been demonstrated in the West [U.S. EPA, 2011]. We find significant differences in estimates of the W126 North American background among the participating models. Therefore, the use of multiple models is crucial in assessing the W126 levels in the absence or reduction of North American anthropogenic emissions. Based on a three-model mean, NAB explains $\sim 30 \%$ of the day-to-day variability in the W126 daily index in the Intermountain West. NAB increases only occasionally on days with high W126 daily index in the California region $(r=0.23)$, and there is no significant correlation of NAB with the W126 DI in the Atlantic region. We find the issue of resolution especially important for the models' ability to reproduce the sharp spatial gradients of W126, particularly in California. The total NAB contribution to daytime ozone is $56-67 \%$, as based on three models, and is $64-78 \%$ for the Intermountain West. However, due to the highly nonlinear dependence of W126 on ozone, W126 in the absence of NA anthropogenic emissions is estimated to be only $4-12 \%$ of the base levels for the contiguous U.S. and is in the range of 9-27\% for the Intermountain West region. The highest NAB contribution is found in the West where the W126 NAB can be up to $35 \%$ of current levels.

[37] To investigate the sources influencing W126 in the U.S., we perform sensitivity analysis using the GEOS-Chem adjoint model, which shows that W126 is most sensitive to the anthropogenic $(58 \%)$ and natural $(25 \%) \mathrm{NO}_{x}$ emissions, followed by NMVOCs $(10 \%)$ and CO (7\%). Eighty percent of sensitivity to the $\mathrm{NO}_{x}$ anthropogenic emissions is within the U.S., followed by emissions in Canada (9\%), Mexico, $(4 \%)$ and China $(3 \%)$. The NAB component of W126 in the U.S. is most sensitive to natural $\mathrm{NO}_{x}$ sources, with lightning and soil being most important. It is important to note that the NAB contribution is expected to vary with the 3 month season, and the impact of long-range transport or stratospheric intrusions can be higher if the analyzed period includes April or March.

[38] This work is the first national-scale source-attribution analysis for W126 and shows that long-range transport of pollution has a minor impact on this metric in the U.S. and that domestic emissions reductions should be effective in lowering W126 levels. While the adjoint sensitivities are determined for the nationwide W126, this analysis targets the areas with the most ozone damage because of the W126 weighting which emphasizes the highest ozone concentrations. It is important to note that the modeled NAB and adjoint sensitivities are only as accurate as the model representation of $\mathrm{W} 126$ and the emissions driving the simulations. Further research is needed to improve the models' performance in the eastern U.S., where most models overestimate surface ozone concentrations. The bias-correction analysis shows that the conclusions based on aggregated adjoint emission sensitivities in this work are not significantly affected by model bias or uncertainties in emission inventories, including the impact of emission uncertainties in one country on sensitivities to emissions in another. Use of the adjoint sensitivities to investigate sources contributing to regional or county-scale average W126, however, will require observation-based bias correction which is subject to availability of ozone measurements. This can be problematic in the high-W126 areas in the rural West, where the monitoring network is currently limited. Future modeling studies will be of value for estimating exposure in areas with limited monitoring.

[39] Future work should expand this analysis by performing source attribution of ozone damage by vegetation and crop type. As the W126 seasonality and NAB levels depend upon location, next steps will focus on a finer spatial scale with study regions chosen based on their W126 levels or based on having high value for the public (e.g., national parks with ozone-sensitive vegetation). As emissions reductions take place as a result of implementing the primary ozone standard, source assessment for W126 will need to be reevaluated.

[40] Acknowledgments. We thank Victoria Sandiford (EPA OAQPS), Jeffrey D. Herrick (EPA/ORD), J. Travis Smith (EPA/ OAQPS), and Ellen Porter (NPS/ARD) for valuable discussion. This work was supported by NASA Air Quality Applied Sciences Team award NNX11AI54G.

\section{References}

Adhikary, B., et al. (2010), A regional scale modeling analysis of aerosol and trace gas distributions over the eastern Pacific during the INTEX-B field campaign, Atmos. Chem. Phys., 10(5), 2091-2115, doi:10.5194/acp-10-2091-2010.

Allen, D. J., K. E. Pickering, R. W. Pinder, B. H. Henderson, K. W. Appel, and A. Prados (2012), Impact of lightning-NO on eastern United States photochemistry during the summer of 2006 as determined using the CMAQ model, Atmos. Chem. Phys., 12(4), 1737-1758, doi:10.5194/acp12-1737-2012.

Arbaugh, M. J., P. R. Miller, J. J. Carroll, B. Takemoto, and T. Procter (1998), Relationships of ozone exposure to pine injury in the Sierra Nevada and San Bernardino Mountains of California, USA, Environ. Pollut., 101(2), 291-301, doi:10.1016/S0269-7491(98)00027-X.

Avnery, S., D. L. Mauzerall, J. Liu, and L. W. Horowitz (2011), Global crop yield reductions due to surface ozone exposure: 1. Year 2000 crop production losses and economic damage, Atmos. Environ., 45(13), 2284-2296, doi:10.1016/j.atmosenv.2010.11.045.

Avnery, S., D. L. Mauzerall, and A. M. Fiore (2013), Increasing global agricultural production by reducing ozone damages via methane emission controls and ozone-resistant cultivar selection, Global Change Biol., 19(4), 1285-1299, doi:10.1111/gcb.12118.

Ayers, G. (2001), Comment on regression analysis of air quality data, Atmos. Environ., 35, 2423-2425.

Brown-Steiner, B., and P. Hess (2011), Asian influence on surface ozone in the United States: A comparison of chemistry, seasonality, and transport mechanisms, J. Geophys. Res., 116, D17309, doi:10.1029/2011JD015846.

Carmichael, G. R., et al. (2003), Evaluating regional emission estimates using the TRACE-P observations, J. Geophys. Res., 108(D21), 8810, doi:10.1029/2002JD003116.

Carter, W. P. L. (2000), Documentation of the SAPRC-99 chemical mechanism for VOC reactivity assessment, final report to California Air Resources Board, Contract no. 92-329 and 95-308.

CASTNET 2009 report (2011), Clean Air Status and Trends Network (CASTNET) 2009 annual report (EPA Contract No. EP-W-09-028), prepared by: MACTEC Engineering and Consulting, Inc.

Chappelka, A., J. Skelly, G. Somers, J. Renfro, and E. Hildebrand (1999), Mature black cherry used as a bioindicator of ozone injury, Water Air Soil Pollut., 116(1-2), 261-266, doi:10.1023/A:1005260422738.

Cohan, D. S., A. Hakami, Y. Hu, and A. G. Russell (2005), Nonlinear response of ozone to emissions: Source apportionment and sensitivity analysis, Environ. Sci. Technol., 39(17), 6739-6748, doi: $10.1021 / \mathrm{es} 048664 \mathrm{~m}$.

Draper, N. R., and H. Smith (1998), Applied Regression Analysis, 706 pp., John Wiley, Hoboken, NJ, USA. 
Emery, C., J. Jung, N. Downey, J. Johnson, M. Jimenez, G. Yarwood, and R. Morris (2012), Regional and global modeling estimates of policy relevant background ozone over the United States, Atmos. Environ., 47, 206-217, doi:10.1016/j.atmosenv.2011.11.012.

Fiore, A., D. J. Jacob, H. Liu, R. M. Yantosca, T. D. Fairlie, and Q. Li (2003), Variability in surface ozone background over the United States: Implications for air quality policy, J. Geophys. Res., 108(D24), 4787, doi:10.1029/2003JD003855.

Fiore, A. M., D. J. Jacob, I. Bey, R. M. Yantosca, B. D. Field, A. C. Fusco, and J. G. Wilkinson (2002), Background ozone over the United States in summer: Origin, trend, and contribution to pollution episodes, J. Geophys. Res., 107(D15), ACH 11-1-ACH 11-25, doi:10.1029/2001JD000982.

Fiore, A. M., et al. (2009), Multimodel estimates of intercontinental source-receptor relationships for ozone pollution, J. Geophys. Res., 114, D04301, doi:10.1029/2008JD010816.

Giering, R., and T. Kaminski (1998), Recipes for adjoint code construction, ACM Trans. Math. Softw., 24(4), 437-474, doi:10.1145/293686.293695.

Guenther, A., T. Karl, P. Harley, C. Wiedinmyer, P. I. Palmer, and C. Geron (2006), Estimates of global terrestrial isoprene emissions using MEGAN (Model of Emissions of Gases and Aerosols from Nature), Atmos. Chem. Phys., 6(11), 3181-3210.

Guenther, A. B., X. Jiang, C. L. Heald, T. Sakulyanontvittaya, T. Duhl, L. K. Emmons, and X. Wang (2012), The Model of Emissions of Gases and Aerosols from Nature version 2.1 (MEGAN2.1): An extended and updated framework for modeling biogenic emissions, Geosci. Model Dev., 5(6), 1471-1492, doi:10.5194/gmd-5-1471-2012.

Hakami, A., J. H. Seinfeld, T. Chai, Y. Tang, G. R. Carmichael, and A. Sandu (2006), Adjoint sensitivity analysis of ozone nonattainment over the continental United States, Environ. Sci. Technol., 40(12), 3855-3864, doi:10.1021/es052135g.

Henderson, B., N. Possiel, F. Akhtar, and H. Simon (2012), Regional and seasonal analysis of North American background ozone estimates from two studies, Prepared for Ozone NAAQS Review Docket EPAHQ-OAR-2012-0699, Aug 2012. [Available at: http://www.epa.gov/ttn/ naaqs/standards/ozone/s_o3_td.html].

Henze, D. K., A. Hakami, and J. H. Seinfeld (2007), Development of the adjoint of GEOS-Chem, Atmos. Chem. Phys., 7(9), 2413-2433, doi:10.5194/acp-7-2413-2007.

Hollaway, M. J., S. R. Arnold, A. J. Challinor, and L. D. Emberson (2012), Intercontinental trans-boundary contributions to ozone-induced crop yield losses in the Northern Hemisphere, Biogeosciences, 9(1), 271-292, doi:10.5194/bg-9-271-2012.

Huang, M., et al. (2010), Impacts of transported background ozone on California air quality during the ARCTAS-CARB period-A multi-scale modeling study, Atmos. Chem. Phys., 10(14), 6947-6968, doi:10.5194/acp-10-6947-2010.

Huang, M., et al. (2013), Impacts of transported background pollutants on summertime western US air quality: Model evaluation, sensitivity analysis and data assimilation, Atmos. Chem. Phys., 13(1), 359-391, doi:10.5194/acp-13-359-2013.

Jacob, D. J., J. A. Logan, and P. P. Murti (1999), Effect of rising Asian emissions on surface ozone in the United States, Geophys. Res. Lett. 26(14), 2175-2178, doi:10.1029/1999GL900450.

Jaffe, D. (2011), Relationship between surface and free tropospheric ozone in the Western U.S., Environ. Sci. Technol., 45(2), 432-438, doi:10.1021/es1028102

Kuhns, H., E. M. Knipping, and J. M. Vukovich (2005), Development of a United States-Mexico emissions inventory for the Big Bend Regional Aerosol and Visibility Observational (BRAVO) study, J. Air Waste Manage. Assoc., 55, 677-692.

Lefohn, A., and V. Runeckles (1987), Establishing a standard to protect vegetation-Ozone exposure/dose considerations, Atmos. Environ., 21, 561-568.

Lefohn, A., J. Lawrence, and R. Kohut (1988), A comparison of indices that describe the relationship between exposure to ozone and reduction in the yield of agricultural crops, Atmos. Environ., 22, 1229-1240.

Lin, M., et al. (2012a), Transport of Asian ozone pollution into surface air over the western United States in spring, J. Geophys. Res., 117, D00V07, doi:10.1029/2011JD016961.

Lin, M., A. M. Fiore, O. R. Cooper, L. W. Horowitz, A. O. Langford, H. Levy, B. J. Johnson, V. Naik, S. J. Oltmans, and C. J. Senff (2012b), J. Geophys. Res., 117, D00V22, doi:10.1029/2012JD018151.

Lin, X., M. Trainer, and S. C. Liu (1988), On the nonlinearity of the tropospheric ozone production, J. Geophys. Res., 93(D12), 15,879-15,888, doi:10.1029/JD093iD12p15879.

Liu, H., D. J. Jacob, I. Bey, R. M. Yantosca, B. N. Duncan, and G. W. Sachse (2003), Transport pathways for Asian pollution outflow over the Pacific: Interannual and seasonal variations, J. Geophys. Res., 108(D20), 8786, doi:10.1029/2002JD003102.
Mao, J., F. Paulot, D. J. Jacob, R. C. Cohen, J. D. Crounse, P. O. Wennberg, C. A. Keller, R. C. Hudman, M. P. Barkley, and L. W. Horowitz (2013), Ozone and organic nitrates over the eastern United States: Sensitivity to isoprene chemistry, J. Geophys. Res. Atmos., 118, 11,256-11,268, doi:10.1002/jgrd.50817.

McDonald-Buller, E. C., et al. (2011), Establishing policy relevant background (PRB) ozone concentrations in the United States, Environ. Sci. Technol., 45(22), 9484-9497, doi:10.1021/es2022818.

McLinden, C. A., S. C. Olsen, B. Hannegan, O. Wild, M. J. Prather, and J. Sundet (2000), Stratospheric ozone in 3-D models: A simple chemistry and the cross-tropopause flux, J. Geophys. Res., 105(D11), 14,653-14,665, doi:10.1029/2000JD900124.

Moss, R. H., et al. (2010), The next generation of scenarios for climate change research and assessment, Nature, 437, 747-756, doi:10.1038/nature08823.

Mueller, S. F., and J. W. Mallard (2011), Contributions of natural emissions to ozone and PM2.5 as simulated by the community multiscale air quality (CMAQ) model, Environ. Sci. Technol., 45(11), 4817-4823, doi:10.1021/es103645m.

Murray, L. T., D. J. Jacob, J. A. Logan, R. C. Hudman, and W. J. Koshak (2012), Optimized regional and interannual variability of lightning in a global chemical transport model constrained by LIS/OTD satellite data, J. Geophys. Res., 117, D20307, doi:10.1029/2012JD017934.

Naik, V., L. W. Horowitz, A. M. Fiore, P. Ginoux, J. Mao, A. M. Aghedo, and H. Levy (2013), Impact of preindustrial to present-day changes in short-lived pollutant emissions on atmospheric composition and climate forcing, J. Geophys. Res. Atmos., 118, 8086-8110, doi:10.1002/jgrd.50608.

Ott, L. E., K. E. Pickering, G. L. Stenchikov, D. J. Allen, A. J. DeCaria, B. Ridley, R.-F. Lin, S. Lang, and W.-K. Tao (2010), Production of lightning NOx and its vertical distribution calculated from three-dimensional cloud-scale chemical transport model simulations, J. Geophys. Res., 115, D04301, doi:10.1029/2009JD011880.

Parrington, M., et al. (2012), The influence of boreal biomass burning emissions on the distribution of tropospheric ozone over North America and the North Atlantic during 2010, Atmos. Chem. Phys., 12(4), 2077-2098, doi:10.5194/acp-12-2077-2012.

Prather, M. J., X. Zhu, Q. Tang, J. Hsu, and J. L. Neu (2011), An atmospheric chemist in search of the tropopause, J. Geophys. Res., 116, D04306, doi:10.1029/2010JD014939.

Reich, P. B., and R. G. Amundson (1985), Ambient levels of ozone reduce net photosynthesis in tree and crop species, Science, 230(4725), 566-570, doi:10.1126/science.230.4725.566.

Reidmiller, D. R., et al. (2009), The influence of foreign vs. North American emissions on surface ozone in the US, Atmos. Chem. Phys., 9(14), 5027-5042, doi:10.5194/acp-9-5027-2009.

Russell, A. R., L. C. Valin, and R. C. Cohen (2012), Trends in OMI $\mathrm{NO}_{2}$ observations over the US: Effects of emission control technology and the economic recession, Atmos. Chem. Phys. Discuss., 12(6), 15,419-15,452, doi:10.5194/acpd-12-15419-2012.

Sandu, A., D. N. Daescu, G. R. Carmichael, and T. Chai (2005), Adjoint sensitivity analysis of regional air quality models, J. Comput. Phys., 204(1), 222-252, doi:10.1016/j.jcp.2004.10.011.

Schaub, M. J. Skelly, J. Zhang, J. Ferdinand, J. Savage, R. Stevenson, D. Davis, and K. Steiner (2005), Physiological and foliar symptom response in the crowns of Prunus serotina, Fraxinus americana and Acer rubrum canopy trees to ambient ozone under forest conditions, Environ. Pol., 133(3), 553-567, doi:10.1016/j.envpol.2004.06.012.

Shindell, D., et al. (2012), Simultaneously mitigating near-term climate change and improving human health and food security, Science, 335(6065), 183-189, doi:10.1126/science.1210026.

Tong, D. Q., R. Mathur, D. Kang, S. Yu, K. L. Schere, and G. Pouliot (2009), Vegetation exposure to ozone over the continental United States: Assessment of exposure indices by the EtaCMAQ air quality forecast model, Atmos. Environ., 724-733(3), doi:10.1016/j.atmosenv.2008.09.084

U.S. EPA (2006), Air quality criteria for ozone and related photochemical oxidants (2006 Final), Washington, D.C., EPA/600/R-05/004aFcF. [Available at http://cfpub.epa.gov/ncea/cfm/recordisplay.cfm? deid $=149923]$.

U.S. EPA (2011), Regulatory Impact Analysis, Final National Ambient Air Quality Standard for Ozone (Draft). [Available at http://www.epa.gov/ glo/actions.html].

U.S. EPA (2013), Integrated Science Assessment for Ozone and Related Photochemical Oxidants (2013), Reserach Triangle Park, NC, EPA/600/R-10/076F. [Available at http://epa.gov/ncea/isa/].

van der Werf, G. R., J. T. Randerson, L. Giglio, G. J. Collatz, M Mu, P. S. Kasibhatla, D. C. Morton, R. S. DeFries, Y. Jin, and T. T. van Leeuwen (2010), Global fire emissions and the contribution of deforestation, savanna, forest, agricultural, and peat fires (1997-2009), 


\section{LAPINA ET AL.: SOURCE CONTRIBUTIONS TO OZONE}

Atmos. Chem. Phys. Discuss., 10(6), 16,153-16,230, doi:10.5194/acpd10-16153-2010.

Van Dingenen, R., F. J. Dentener, F. Raes, M. C. Krol, L. Emberson, and J. Cofala (2009), The global impact of ozone on agricultural crop yields under current and future air quality legislation, Atmos. Environ., 43(3), 604-618, doi:10.1016/j.atmosenv.2008.10.033.

Walker, T. W., et al. (2012), Impacts of midlatitude precursor emissions and local photochemistry on ozone abundances in the Arctic, J. Geophys. Res., 117, D01305, doi:10.1029/2011JD016370.

Wang, H., D. J. Jacob, P. L. Sager, D. G. Streets, R. J. Park, A. B. Gilliland, and A. van Donkelaar (2009), Surface ozone background in the United States: Canadian and Mexican pollution influences, Atmos. Environ., 43(6), 1310-1319, doi:10.1016/j.atmosenv.2008.11.036.

Wang, Y., D. J. Jacob, and J. A. Logan (1998), Global simulation of tropospheric $\mathrm{O}_{3}$-NOx-hydrocarbon chemistry: 1 . Model formulation, $J$. Geophys. Res., 103(D9), 10,713-10,725, doi:10.1029/98JD00158.

Wiedinmyer, C., S. K. Akagi, R. J. Yokelson, L. K. Emmons, J. A. Al-Saadi, J. J. Orlando, and A. J. Soja (2011), The Fire INventory from NCAR (FINN): A high resolution global model to estimate the emissions from open burning, Geosci. Model Dev., 4(3), 625-641, doi:10.5194/gmd4-625-2011.

Wild, O., et al. (2012), Modelling future changes in surface ozone: A parameterized approach, Atmos. Chem. Phys., 12(4), 2037-2054, doi:10.5194/acp-12-2037-2012.
Wu, S., L. J. Mickley, D. J. Jacob, J. A. Logan, R. M. Yantosca, and D. Rind (2007), Why are there large differences between models in global budgets of tropospheric ozone?, J. Geophys. Res., 112, D05302, doi:10.1029/2006JD007801.

Wu, S., B. N. Duncan, D. J. Jacob, A. M. Fiore, and O. Wild (2009), Chemical nonlinearities in relating intercontinental ozone pollution to anthropogenic emissions, Geophys. Res. Lett., 36, L05806, doi:10.1029/2008GL036607.

Zhang, L., D. J. Jacob, M. Kopacz, D. K. Henze, K. Singh, and D. A. Jaffe (2009a), Intercontinental source attribution of ozone pollution at western U.S. sites using an adjoint method, Geophys. Res. Lett., 36, L11810, doi:10.1029/2009GL037950.

Zhang, L., D. J. Jacob, N. V. Downey, D. A. Wood, D. Blewitt, C. C. Carouge, A. van Donkelaar, D. B. Jones, L. T. Murray, and Y. Wang (2011), Improved estimate of the policy-relevant background ozone in the United States using the GEOS-Chem global model with $1 / 2 \times 2 / 3$ horizontal resolution over North America, Atmos. Environ., 45(37), 6769-6776, doi:10.1016/j.atmosenv.2011.07.054.

Zhang, Q., et al. (2009b), Asian emissions in 2006 for the NASA INTEXB mission, Atmos. Chem. Phys., 9(14), 5131-5153, doi:10.5194/acp-95131-2009. 